\title{
Merger Activity In Industry Equilibrium
}

\author{
Theodosios Dimopoulos ${ }^{\dagger}$
}

\author{
Stefano Sacchetto ${ }^{\dagger \dagger}$
}

\begin{abstract}
We study the effects of mergers and acquisitions on industry dynamics. We develop an infinite horizon model of a competitive industry, which features mergers, entry, exit, and investment by heterogeneous firms. Merger synergies arise from improvements in productivity and cost efficiencies. We characterize the time-series and cross-sectional evolution of firm productivities and merger opportunities in a rational expectations equilibrium. Consistent with the empirical evidence, our model generates procyclical entry and merger activity, as well as counter-cyclical exit. The presence of a merger market induces higher entry rates and lower exit rates, reduces the counter-cyclicality of exit, and increases the mean and variance of the cross-sectional distribution of firm-level productivities. While entry and exit induce the mean productivity to be counter-cyclical, this pattern is reversed when the possibility of mergers is taken into account.
\end{abstract}

JEL Classifications: D21, D92, E22, E32, G34, L11

Keywords: Mergers, Industry Equilibrium

\footnotetext{
${ }^{*}$ We are grateful to seminar participants at the $9^{\text {th }}$ FINRISK conference in Gerzensee. First draft, please do not cite without the authors' permission. All remaining errors are our responsibility.

$\dagger$ Swiss Finance Institute, and University of Lausanne. Address: Institut de banque et finance (IBF), HEC Lausanne, Université de Lausanne, Extranef 237, 1015, Lausanne, Switzerland. Phone: +1-41-21-692-3398. Email: Theodosios.Dimopoulos@unil.ch.

†† Tepper School of Business, Carnegie Mellon University. Address: Tepper School of Business, 5000 Forbes Avenue, Pittsburgh, PA 15213, USA. Phone:+1-412-268-8832. E-mail: sacchetto@cmu.edu.
} 


\section{Introduction}

Mergers and acquisitions (M\&A) have a significant impact on the evolution of industries. They account for a large fraction of firm turnover, facilitate the redeployment of capital to productive uses, and accelerate the transmission of new technologies among firms. For the parties involved, M\&As represent complex investment decisions, as companies weigh the value of the synergies generated in a given deal against future takeover opportunities.

Figure 1 highlights two stylized facts about aggregate merger and exit activity ${ }_{1}^{1}$ First, M\&As account for a large portion of firm turnover: between 1981 and 2010, approximately $4.5 \%$ of active firms merged in a given year, while the exit rate due to poor performance was $3.7 \%$. Second, merger activity is procyclical, which has been documented by a large body of empirical work (e.g., Andrade, Mitchell, and Stafford, 2001; Harford, 2005), whereas exit is counter-cyclical (Campbell, 1998).

What determines the joint dynamics of mergers, exit, and entry over the business cycle? What are the effects of merger activity on the evolution of the cross-section of firms in the industry? To answer these questions, we develop an infinite horizon model of a competitive industry populated by firms with heterogeneous productivities. In each period, potential entrants decide whether to pay an entry cost and invest in productive capital. Incumbents choose the capital stock and decide whether to exit the industry. They also participate in the market for corporate control, by which potential takeover matches are formed. Merger synergies are generated by improvements in productivity and reductions in the fixed costs of production. Conditional on deciding to merge, the terms of exchange are decided by Nash bargaining between the two firms, and a fixed merger implementation cost is incurred. The bargaining framework accounts endogenously for potential future takeover opportunities, should one of the parties refuse to accept the deal. Because firms face persistent aggregate and idiosyncratic productivity shocks, they are heterogeneous in terms of both the current synergies and future takeover opportunities.

In the model, potential entrants choose to exercise their entry option whenever a signal

\footnotetext{
${ }^{1} \mathrm{M} \& \mathrm{~A}$ activity and exit rates are measured by the fraction of public firms in CRSP that are delisted in a given year because of a merger (Figure 1a) or poor performance (Figure 1b), respectively. See Appendix A for a detailed description of the delisting codes used to measure mergers and exit activity. These rates are partly affected by the fact that CRSP coverage increased substantially in 1962 to include AMEX firms and in 1972 to include NASDAQ firms.
} 
about their own future productivity exceeds a certain threshold. Similarly, incumbents leave the industry when their idiosyncratic productivity drops below an exit threshold. Conditional on being matched, incumbent firms agree to merge whenever the productivity and cost synergies are high enough to compensate for the merger implementation costs.

We characterize the time-series and cross-sectional evolution of firm productivities and merger opportunities in a rational expectations equilibrium by employing the Krusell and Smith (1998) algorithm. We then calibrate the model using cross-sectional and time-series moments that describe M\&A activity, entry, and exit in the data.

The main contribution of our paper is to characterize the interactions between merger activity and firms' entry and exit decisions in industry equilibrium. Our model replicates a number of features that are consistent with the empirical evidence. First, the model generates procyclical entry and counter-cyclical exit. This result stems from a selection effect: in periods of positive aggregate shocks, the threshold productivity levels for entry and exit decrease. Second, when aggregate productivity rises, the value of merger synergies is higher, and M\&A activity increases. To better understand this result, notice that, in our framework, M\&A activity is either procyclical or counter-cyclical, depending on the relative importance of the two sources of merger synergies: a reduction in the fixed cost of production, and an increase in marginal productivity. Cost reductions are more relevant during periods of low aggregate productivity, thus inducing counter-cyclicality: firms merge in bad times in order to reduce costs and avoid making an exit. The second source of synergies is procyclical, because of the specification of period profits, which are multiplicative in the firms' idiosyncratic and aggregate productivity shocks. At the calibrated parameters, the effect of increased productivity dominates and aggregate merger activity is procylcical.

Second, to highlight the effects of the merger market on industry dynamics, we perform a comparative statics exercise and contrast our calibration results to the case in which the matching rate among firms is set to zero. We find that merger opportunities produce higher entry and lower exit rates in the industry. Firms have stronger incentives to stay in the market because the option to merge is valuable, and new firms are born with the prospect of potential involvement in a future takeover. This implies that poorly performing firms become less susceptible to economic recessions, which means that merger activity reduces the 
counter-cyclicality of the exit rate. Mergers also have important effects on the cross-section of firms, as they induce a higher mean and variance of firm-level productivity. Accordingly, average firm size, sales, and profitability increase, whereas the average investment rate declines, due to the assumption of decreasing returns to scale.

Finally, we show how M\&A activity affects the dynamics of the cross-sectional distribution of firm productivities over the business cycle. In the absence of merger options, the average idiosyncratic productivity is negatively correlated with aggregate productivity shocks, since worse performing firms choose to enter or to remain in the industry during periods of economic expansion. We show that this pattern is largely reversed when the possibility of mergers is taken into account. Procyclical merger synergies lead to takeover waves that are positively correlated with aggregate productivity shocks and to improvements in average idiosyncratic productivity during booms.

Our paper contributes to a wide body of research on M\&A activity $\left.\right|^{2}$ First, our model relates to theoretical studies of merger synergies. Jovanovic and Rousseau (2002) propose a Q-theory of mergers, according to which takeovers are a tool to reallocate capital from underperforming firms to those with better management or productive resources. One of the main predictions of this theory concerns "who buys whom": high-productivity firms should take over the assets of low-productivity firms. Rhodes-Kropf and Robinson (2008) challenge the Q-theory based on empirical evidence that contrasts this prediction. They show that, rather than "high buys low", mergers usually happen between firms with similar market-to-book ratios, so that a better description of the merger market would be "like buys like". To rationalize this fact, Rhodes-Kropf and Robinson (2008) formulate a model in which merger synergies stem from the combination of complementary assets. A recent paper that builds on the idea of complementarities is Levine (2011). In his model, firms with high revenue growth opportunities, but high operating costs, become takeover targets of firms with lower growth prospects, but higher cost efficiency. Finally, another possible source of synergies are economies of scope that allow the merged firms to lower their fixed costs of production by eliminating redundant or inefficient activities (Gomes and Livdan, 2004). In our paper, rather than specifying merger gains according to one of these theories,

\footnotetext{
${ }^{2}$ See Betton, Eckbo, and Thorburn (2008) and Gaughan (2011) for surveys of this literature.
} 
we use a flexible specification that incorporates as sources of synergies both productivity gains and reductions in the fixed costs of production. Depending on the parameter values, productivity gains may be maximized when the productivity gap between the merging firms is large or small. In this sense, our paper is closest to David (2011), who studies an endogenous-search model of mergers and acquisitions among firms with heterogeneous productivities that are constant over time. Compared to David (2011), our model allows for aggregate productivity shocks, time-varying idiosyncratic shocks, endogenous exit, and growth by investment in capital stock.

Second, our paper contributes to the theoretical literature on industry dynamics in economies with heterogeneous firms. A seminal paper in this literature is Hopenhayn (1992), who characterizes the entry and exit levels in stationary industry equilibrium. In recent work that builds on Hopenhayn's framework, Lee and Mukoyama (2012) and Clementi and Palazzo (2010) introduce aggregate productivity shocks and analyze the dynamics of firms' entry and exit decisions over the business cycle $3^{3}$ Our main contribution to this literature is to introduce a merger market in which firms can combine their assets and endogenously enhance their productivities. Thus, our model has predictions about the joint dynamics of mergers, entry, exit, investment, and the cross-sectional distribution of firms' productivities over the business cycle.

Third, there is a vast body of work in industrial organization that studies the effects of mergers on product-market competition and derives implications for antitrust policy (see Whinston, 2007). Our paper is related in particular to Gowrisankaran (1999), who analyzes a dynamic game-theoretic model of horizontal mergers in oligopolistic industries, featuring endogenous investment, entry and exit. While he focuses on increased market power as a source of merger gains, synergies in our paper are generated by productivity improvements and cost reductions in perfectly competitive industries.

Finally, our paper relates to the empirical research on the time-series properties of merger activity. In particular, two important properties are that mergers occur in waves, and that merger activity is positively correlated with industry-wide technological, economic

\footnotetext{
${ }^{3}$ Other examples of general equilibrium models with heterogeneous firms are Khan and Thomas (2008), who analyze the effects of capital adjustment costs on aggregate investment, and Gomes and Schmid (2010), who focus on the asset pricing implications of firm heterogeneity and entry and exit activity.
} 
and regulatory shocks (Andrade, Mitchell, and Stafford, 2001; Harford, 2005; Jovanovic and Rousseau, 2008; Dittmar and Dittmar, 2008).4 Eisfeldt and Rampini (2006) find that the correlation of capital reallocation and GDP over the business cycle is highly positive and significant. Consistent with these findings, our calibration results produce a positive correlation between aggregate productivity shocks and merger activity.

The paper proceeds as follows. Section 2 develops a model of industry dynamics with mergers, entry, and exit; section 3 presents the calibration procedure and section 4 presents the results. Section 5 discusses a number of avenues for future research and concludes. Appendix A describes the sample construction and includes the definitions of the empirical variables, while Appendix B contains the details of the numerical procedure used in the calibration.

\section{Model}

We model the dynamics of an industry populated by a continuum of firms with symmetric information. Time is discrete and the horizon is infinite. The population of firms is divided between incumbents with mass $N$ and potential entrants, with mass $N_{E}$. In each period, incumbents participate in a merger market, produce and realize profits, invest to accumulate productive capital, and decide to stay or exit the industry. Potential entrants observe a signal about their own productivity and decide whether to enter the industry by paying a fixed cost.

The timing of events, summarized in Figure 2, is as follows: incumbent firms observe the realizations of the aggregate state variables $x$ and their own productivity level $z$; at the same time, potential entrants observe $x$ and their productivity signal, $y$; matching pairs of incumbent firms are drawn and decide to merge or not; potential entrants make their entry decisions; incumbents choose whether to stay or exit the industry. Finally, production and period profits are realized, and investment decisions are made.

\footnotetext{
${ }^{4}$ See also Rhodes-Kropf, Robinson, and Viswanathan (2005), who find that a significant fraction of merger activity can be explained by market misvaluation.
} 


\subsection{Production and Profits}

Each firm employs capital $k$ to produce per-period operating profits $\pi(s, z, k)=s z k^{\alpha}-$ $c_{f}$, where $\alpha \in(0,1), z \in \mathcal{Z}=[\underline{z}, \bar{z}]$ is a firm-specific productivity shock, and $s \in \mathcal{S}=[\underline{s}, \bar{s}]$ is an industry-wide productivity shock. We assume that $\underline{z} \geq 0$ and $\underline{s} \geq 0$. The idiosyncratic shock is independently distributed across firms. Both the idiosyncratic and aggregate shocks are time-persistent and characterized by the conditional cumulative distributions $F_{Z}\left(z^{\prime} \mid z\right)$ and $F_{S}\left(s^{\prime} \mid s\right)$, respectively. Throughout the paper, primes denote next-period values. Firms can buy and sell capital at unit price, and capital depreciates at rate $\delta \in(0,1)$. The investment expenditure of a firm is $I=k^{\prime}-(1-\delta) k$. Firms are risk neutral and discount the stream of future operating profits at rate $r$.

\subsection{Mergers and Exit}

In each period, incumbent firms participate in a market for corporate control. In that market, merger offers arrive randomly at rate $\mu \in[0,1]$. Conditional on the formation of a takeover match, the two firms negotiate the merger terms according to a Nash bargaining process with equal bargaining power. Firms choosing to merge in a given period combine operations in the next period. Namely, in the period in which firms $i$ and $j \neq i$ merge, the profits of the new merged firm $M$ is the sum of the profits of the two separate firms. In the same period, the merged firm pays a one-off integration cost $c_{M} \geq 0$.

Organizational changes result in a new idiosyncratic productivity level $\zeta_{M}\left(z_{i}, z_{j}\right)$, and

the next period idiosyncratic shock $z^{\prime}$ will be drawn according to $F_{Z}\left(z^{\prime} \mid \zeta_{M}\left(z_{i}, z_{j}\right)\right)$. The merged firm's idiosyncratic productivity depends on the respective quantities of firm $i$ and $j$, and it is given by

$$
\zeta_{M}\left(z_{i}, z_{j}\right)=\underline{z}+(\bar{z}-\underline{z})\left[\lambda \max \left\{\tilde{z}_{i}, \tilde{z}_{j}\right\}+(1-\lambda) \min \left\{\tilde{z}_{i}, \tilde{z}_{j}\right\}\right]^{\theta}
$$

where $\tilde{z}=\frac{z-\underline{z}}{\bar{z}-\underline{z}}, \lambda \geqslant 0$, and $0<\theta<1$. We scale the function $\zeta_{M}\left(z_{i}, z_{j}\right)$ so that it does not assume values outside the closed interval $[\bar{z}, \underline{z}]$. We provide a discussion of our specification of merger productivity gains in subsection 2.5 . 
After mergers take place, firms decide whether to stay or exit the industry. Exit decisions are implemented at the end of the period. Hence, the payoff of an exiting firm consists of the period payoff and the liquidation value of capital.

\subsection{Entry}

In each period, there is a pool of potential entrants with mass $N_{E}$. At the beginning of the period, potential entrants observe a signal $y$ regarding their idiosyncratic productivity level that is drawn from a time-invariant distribution $G(y)$, and they decide whether to pay an entry $\operatorname{cost} c_{E}$. Entrants are not immediately productive, since they have no capital at their disposal, but they can invest to accumulate capital for production in the next period, when their productivity is distributed as $F_{Z}\left(z^{\prime} \mid y\right)$. Moreover, they do not participate in the merger market for the period in which they make their entry decision.

\subsection{Equilibrium}

Denote the aggregate states as $x \in \mathcal{X}$, with transition function $F_{X}\left(x_{t+1} \mid x_{t}\right)$. As we discuss below, $x$ is composed of the aggregate productivity shock $s$ and the cross-sectional distribution of capital and idiosyncratic productivities, which we denote by $H(z, k)$. At the investment stage, the incumbents' value function is:

$$
V(x, z, k)=\max _{k^{\prime}} \pi(s, z, k)+(1-\delta) k+\max \left[-k^{\prime}+\frac{1}{1+r} V C\left(x, z_{i}, k^{\prime}\right), 0\right] .
$$

In the above formula, $V C$ denotes the expected end-of-period continuation value, and it incorporates both the possibility that in the next period the firm merges or it remains independent. The firm decides to exit whenever the net present value of continuation is negative:

$$
U(x, z) \equiv \max _{k^{\prime}}-k^{\prime}+\frac{1}{1+r} V C\left(x, z, k^{\prime}\right)<0 .
$$


By assumption, in the period in which two firms agree on a merger, their operating profits remain unaffected. Therefore, the value function of the merged firm is

$V_{M}\left(x, z_{i}, z_{j}, k_{i}, k_{j}\right)=\pi\left(s, z_{i}, k_{i}\right)+\pi\left(s, z_{j}, k_{j}\right)+(1-\delta)\left(k_{i}+k_{j}\right)+\max \left[U\left(x, \zeta_{M}\left(z_{i}, z_{j}\right)\right), 0\right]-c_{M}$.

Synergies are therefore independent of capital levels:

$$
\begin{aligned}
W\left(x, z_{i}, z_{j}\right) & \equiv V_{M}\left(x, z_{i}, z_{j}, k_{i}, k_{j}\right)-V\left(x, z_{i}, k_{i}\right)-V\left(x, z_{j}, k_{j}\right)-c_{M} \\
& =\max \left[U\left(x, \zeta_{M}\left(z_{i}, z_{j}\right)\right), 0\right]-\max \left[U\left(x, z_{i}\right), 0\right]-\max \left[U\left(x, z_{j}\right), 0\right]-c_{M}
\end{aligned}
$$

Two firms, $i$ and $j$, matched in the market for corporate control, merge only if they produce positive synergies, that is if $W\left(x, z_{i}, z_{j}\right) \geq 0$. Since firms find a match with probability $\mu$ per period, and merger synergies are split equally, the end-of-period continuation value of the stand-alone firm is

$$
V C\left(x, z_{i}, k^{\prime}\right)=\int_{\mathcal{Z}^{2}} \int_{\mathcal{X}}\left[V\left(x^{\prime}, z_{i}^{\prime}, k^{\prime}\right)+\frac{\mu}{2} \max \left\{W\left(x^{\prime}, z_{i}^{\prime}, z_{j}^{\prime}\right), 0\right\}\right] d F_{X}\left(x^{\prime} \mid x\right) d F_{\eta}\left(z_{i}^{\prime}, z_{j}^{\prime} \mid z_{i}, x\right)
$$

where

$$
F_{\eta}\left(z_{i}^{\prime}, z_{j}^{\prime} \mid z_{i}, x\right)=F_{Z}\left(z_{i}^{\prime} \mid z_{i}\right) \times F_{Z}\left(z_{j}^{\prime} \mid z_{j}\right) \times \int_{\mathbb{R}^{+}} H\left(z_{j}, k\right) d k .
$$

Since potential entrants lack productive capital, they make their entry decision by comparing their continuation value to the cost of entry. Their value function is the solution to:

$$
V_{E}(x, y)=\max \left[U(x, y)-c_{E}, 0\right] .
$$

We now define the recursive competitive equilibrium in the economy. Let $\mathcal{E}(x)=\{y \in \mathcal{Z}$ : $\left.U(x, y)>c_{E}\right\}$ be the set of the new entrant's shocks, $\epsilon(x)=\{z \in \mathcal{Z}: U(x, z)>0\}$ be the set of non-exiting firms' signals, $\mathcal{M}(x)=\left\{\left(z_{i}, z_{j}\right) \in \mathcal{Z}^{2}: W\left(x, z_{i}, z_{j}\right)>0\right\}$ be the set of merging firms' shocks, and $\mathcal{N}(x)=\left(\mathcal{Z}^{2}-\mathcal{M}(x)\right) \cap(\epsilon(x) \times \mathcal{Z})$ be the set of shocks of firms that do not exit and choose not to merge, even if they are presented with a potential takeover match. In addition, denote the respective probabilities of these sets by $P_{E}(x)=\operatorname{Pr}(y \in \mathcal{E}(x)), P_{\epsilon}(x)=$ 
$\operatorname{Pr}(z \in \epsilon(x)), P_{M}(x)=\operatorname{Pr}\left(\left(z_{i}, z_{j}\right) \in \mathcal{M}(x)\right), P_{N}(x)=\operatorname{Pr}\left(\left(z_{i}, z_{j}\right) \in \mathcal{N}(x)\right)$.

The recursive competitive equilibrium is a collection of value functions $V(x, z, k), V_{E}(x, y)$, a policy function $\kappa(x, z)$, which represents the firm's next-period capital choice, crosssectional densities of incumbent's productivities $f_{t}(Z)$, and incumbent's measures $N_{t}$, such that

1. $V(x, z, k)$ and $\kappa(x, z)$ solve the incumbent's problem;

2. $V_{E}(x, y)$ and $\kappa(x, y)$ solve the potential entrant's problem;

3. For all Borel sets $Z \in \mathcal{Z}$ and for all $t \geq 0$ :

$$
f_{t+1}(Z)=f_{t+1}\left(Z \mid E_{t}=1\right) \operatorname{Pr}\left(E_{t}=1\right)+f_{t+1}\left(Z \mid E_{t}=0\right) \operatorname{Pr}\left(E_{t}=0\right),
$$

where $\operatorname{Pr}\left(E_{t}=1\right)=\frac{N_{E}}{N_{E}+N_{t}}$, is the probability that an idiosyncratic shock observation in period $t+1$ corresponds to a new entrant $\left(E_{t}=1\right)$ in period $t$, and $\operatorname{Pr}\left(E_{t}=0\right)=$ $\frac{N_{t}}{N_{E}+N_{t}}$. The probability density function of the productivity shock of the new entrants is

$$
f_{t+1}\left(Z \mid E_{t}=1\right)=\int_{\mathcal{E}\left(x_{t}\right)} f_{Z}(Z \mid y) \frac{g(y)}{P_{E}\left(x_{t}\right)} d y
$$

while that of incumbents is

$$
\begin{aligned}
f_{t+1}\left(Z \mid E_{t}=0\right) & =(1-\mu) \int_{\epsilon\left(x_{t}\right)} f_{Z}\left(Z \mid z_{t}\right) \frac{f_{t}\left(z_{t}\right)}{P_{\epsilon}\left(x_{t}\right)} d z_{t} \\
& +\mu \int_{\mathcal{M}\left(x_{t}\right)} f_{Z}\left(Z \mid \zeta_{M}\left(z_{t}, z_{j t}\right)\right) f_{t}\left(z_{t}\right) f_{t}\left(z_{j t}\right) d z_{t} d z_{j t} \\
& +\mu \frac{1-P_{M}\left(x_{t}\right)}{P_{N}\left(x_{t}\right)} \int_{\mathcal{N}\left(x_{t}\right)} f_{Z}\left(Z \mid z_{t}\right) f_{t}\left(z_{t}\right) f_{t}\left(z_{j t}\right) d z_{t} d z_{j t},
\end{aligned}
$$

where the first line corresponds to firms that are not matched with a partner $j$ and do not exit the industry, the second line to incumbents that are matched with a partner and merge, and the third line to firms that choose not to merge but stay in the industry; 
4. The dynamics of the incumbent's measure follows the law

$$
N_{t+1}=N_{t}\left[(1-\mu) P_{\epsilon}\left(x_{t}\right)+\mu\left(P_{M}\left(x_{t}\right) / 2+P_{N}\left(x_{t}\right)\right)\right]+N_{E} P_{E}\left(x_{t}\right) .
$$

\subsection{Discussion}

A number of remarks on the model's assumptions are in order. There are two potential gains that are realized when firms merge. First, economies of scope are generated by a reduction in the fixed costs of production (Gomes and Livdan, 2004). While total perperiod costs for the two separate firms are $2 c_{f}$, fixed costs for the merged firm are half at $c_{f}$. These savings may come from lower administrative costs and overhead expenses or the elimination of redundant activities. The gains in cost efficiency are partially reduced by the one-off fixed costs of merger implementation and integration $\left(c_{M}\right)$. Examples of such costs are the expenses incurred to integrate the two firms' information technology systems, business processes, and organizational structures (Tafti, 2011).

Increased productivity is the second potential source of merger synergies. This effect is captured in our model by the function $\zeta_{M}\left(z_{i}, z_{j}\right)$ in Equation 1, which assigns a new productivity level to the merged firm given those of the two merging firms. The specification

in Equation 1 reflects the implications of two important sources of merger gains that have been analyzed in the prior literature. The Q-theory of mergers in Jovanovic and Rousseau (2002) implies that $\lambda=1$ and $\theta=1$, in which case $\zeta_{M}\left(z_{i}, z_{j}\right)=\max \left(z_{i}, z_{j}\right)$, so that the largest improvements occur when firms with very different productivity levels merge. Instead, as the value of $\lambda$ declines, the gains are largest for firms with similar levels of productivity. This effect is shared by Rhodes-Kropf and Robinson (2008), who develop a model of merger synergies based on complementary assets. Figure 3 illustrates the effects of parameter $\lambda$ on productivity gains, plotting the $\zeta_{M}$ function for the two extreme cases of $\lambda=1$ and $\lambda=0$.

Finally, we assume that the merger surplus is split according to a Nash bargaining process in which firms have equal bargaining weights. The assumption of an equal split of the surplus is consistent with the empirical results in Ahern (2012) and David (2011), who find that the total dollar gains from mergers are only marginally higher for targets 
compared to bidders.5

\section{Calibration}

To investigate the implications of the model for the joint dynamics of entry, exit and mergers, we solve the model numerically and perform a calibration exercise. In this section, we first describe the parameterization of the model and the solution algorithm. We then discuss the choice of empirical moments to use as calibration targets and the resulting parameter values.

\subsection{Parameterization and Solution Algorithm}

The system of equations (2)-(6) shows that the value function that summarizes the present value of firm-specific payoffs depends on the cross-sectional distribution of productivity and capital. At the investment stage, merger decisions of the period have been sunk. The firm's value function incorporates the anticipated productivity and capital of a potential match in the next period. Both quantities depend on the current period cross-sectional distribution of idiosyncratic productivities. This distribution is an infinitely dimensional object, so the need arises to approximate it for calibration purposes with a finite set of moments. The idea of summarizing a distribution state variable with a finite set of moments was first pioneered by Krusell and Smith (1998). They study a heterogeneous-agent model of production and consumption with uninsurable labor income shocks and advocate summarizing the cross-sectional distribution of capital in the agent's set of states by its first moment. In our setting, given the specification of the merged firms' productivity gains in Equation 1, the dispersion of firm-specific productivities is an important determinant of synergies. We therefore summarize the cross-sectional distribution of idiosyncratic productivities by its first two moments. Accordingly, firms form state-contingent expectations about the time series dynamics of the distribution by means of a vector auto-regression

\footnotetext{
${ }^{5}$ Cumulative abnormal percentage returns are on average larger for the target companies (Andrade, Mitchell, and Stafford, 2001). However, since percentage returns are affected by the relative size of bidders and targets, inference of bargaining weights based on this measure can be misleading (Ahern, 2012).
} 
forecasting rule:

$$
\left[\begin{array}{c}
m^{\prime} \\
\log \left(v^{\prime}\right)
\end{array}\right]=A_{0}+A_{1}\left[\begin{array}{c}
m \\
\log (v)
\end{array}\right]+A_{2}\left[\begin{array}{c}
\log \left(s^{\prime}\right) \\
\log (s)
\end{array}\right]
$$

where $m$ and $v$ are, respectively, the cross-sectional mean and variance of incumbents' idiosyncratic log productivities. Aggregate states are then summarized by $x \equiv(s, m, v)$.

We describe the dynamics of both the idiosyncratic and the aggregate shocks by means of $\operatorname{AR}(1)$ processes: $\log \left(z^{\prime}\right)=\rho_{z} \log (z)+\sigma_{z} \varepsilon_{z}$ and $\log \left(s^{\prime}\right)=\rho_{s} \log (s)+\sigma_{s} \varepsilon_{s}$, where $\rho_{z}, \rho_{s} \in$ $[0,1), \sigma_{s}, \sigma_{z}>0$, and $\varepsilon_{z}$ and $\varepsilon_{s}$ are uncorrelated standard normal white noise processes.

Since no productivity changes are assumed to take place during the first year of a merger, the optimal capital choice can be shown to satisfy $k^{\prime}=\kappa(s, z)=\left[\frac{a z^{\rho z} s^{\rho_{s}} \exp \left(\frac{\sigma_{s}^{2}+\sigma_{z}^{2}}{2}\right)}{r+\delta}\right]^{\frac{1}{1-a}}$. This policy function leads to a transformation of the Bellman equation which greatly reduces the problem of dimensionality. Indeed, evaluating Equation 6 at optimal capital choices and taking expectations conditional on $s, m, v$ and $z$ we obtain, with a slight abuse of notation:

$$
\begin{aligned}
V C(s, m, v, z) & =E\left[s^{\prime} z^{\prime} \kappa(s, z)^{a}-c_{f}+(1-\delta) \kappa(s, z)+\max \left\{-\kappa\left(s^{\prime}, z^{\prime}\right)+V C\left(s^{\prime}, m^{\prime}, v^{\prime}, z^{\prime}\right), 0\right\}\right. \\
& \left.+\frac{1}{2} \mu \max \left\{W\left(s^{\prime}, m^{\prime}, v^{\prime}, z^{\prime}, z_{2}^{\prime}\right), 0\right\} \mid(s, m, v, z)\right] .
\end{aligned}
$$

Substituting (3) and (5) into (12), we form a Bellman equation independent of the firm's capital level, which we solve by value function iteration (see Judd, 1998). To do so, we discretize the state space for $z$ following Tauchen (1986), by assuming that $\log (z)$ lies in an equally spaced grid in the interval $\left[\frac{-5 \sigma_{z}}{\sqrt{1-\rho_{z}^{2}}}, \frac{5 \sigma_{z}}{\sqrt{1-\rho_{z}^{2}}}\right]$. We choose a large number of standard deviations of the ergodic distribution of the process of $\log (z)$ to obtain a large enough range to incorporate post-merger productivity changes ${ }^{6}$ For the log of the aggregate productivity shock $s$, we employ an equally-spaced grid spanning three standard deviations of the ergodic distribution. The grid for $m$ is initially set to be the same as the grid for $z$. The points of $\log (v)$ lie in an equally-spaced grid in the interval $\left[\log \left(\frac{1}{4} \frac{\sigma_{z}^{2}}{1-\rho_{z}^{2}}\right), \log \left(4 \frac{\sigma_{z}^{2}}{1-\rho_{z}^{2}}\right)\right]$. The grids of both $m$ and $v$ are periodically reset throughout the optimization to reflect the simulated cross-sectional distributions. For each state we use 10 gridpoints.

\footnotetext{
${ }^{6}$ We verify by Monte Carlo experiments that these bounds are never reached.
} 
To evaluate the expectation of the value function, we need to compute a multidimensional integral over future values of aggregate and idiosyncratic shocks. For this purpose, we use the monomial rules proposed in Judd, Maliar, and Maliar (2011). This integration approach results in substantial savings in computational burden while preserving numerical accuracy. Finally, we interpolate the value function at out-of-grid points by linear interpolation.

Our calibration algorithm nests three loops. The first loop finds the solution to the firm's problem, given a set of expectation coefficients $\left(A_{0}, A_{1}, A_{2}\right)$. In the second loop, we simulate the economy for a number of periods, estimate the VAR coefficients on the simulated data, and collect a vector of simulated moments. In total, we simulate 1,000 periods and discard the first 200 to facilitate estimation on the basis of moments in the steady state. Since firms make three types of discrete decisions - entry, exit and mergers - a straightforward Monte Carlo approach would result in a non-smooth optimization surface. To ensure convergence, we follow a non-stochastic simulation approach that traces a continuum of firms over time (see Appendix B for details). In the third loop, the parameter space is searched until the sum of squared deviations between the set of empirical and simulated moments chosen for calibration is minimized.

\subsection{Calibration Targets}

Before describing our choice for the set of parameter values used in the calibration, notice that the measure of potential entrants, $N_{E}$, affects the size of the simulated economy, but not the simulated moments in the steady state. This feature of our model is common to other studies (e.g., Clementi and Palazzo, 2010). In the calibration, we set the number of incumbents in the first period to $N=1,000$ and the number of potential entrants to $N_{E}=100$.

Table 1 displays the parameter values used in the calibration. One period in the simulation is assumed to correspond to one year. The parameters in Panel A are consistent with those used in prior studies that share the same specification of operating profits.7 First,

\footnotetext{
${ }^{7}$ See Hennessy and Whited (2007) and Riddick and Whited (2009). The parameter values used in these studies are typically different from those in real business cycle models that feature labor as a production
} 
we set the discount rate to $r=4 \%$ and capital depreciation to $\delta=15 \%$. Second, we follow Eisfeldt and Muir (2012) and set the curvature of the profit function to $\alpha=0.75$, the persistence of idiosyncratic shocks to $\rho_{z}=0.66$, the standard deviation to $\sigma_{z}=0.11$, and the persistence and standard deviation of the aggregate shocks to $\rho_{s}=0.66$ and $\sigma_{s}=0.03$, respectively.

The six parameters in Panel B of Table 1 are calibrated to match a number of empirical moments, which are reported in Table 2. The sample period used to compute these moments is 1981 to 2010, and the sources of data are SDC Platinum for information on merger deals, CRSP for exit and merger activity, and Compustat for financial information on targets and acquirers. Appendix Adescribes in detail the sample construction and provides definitions of the empirical variables.

The first set of parameters concerns merger activity. We start by computing the average annual takeover rate, measured by the fraction of firms in the CRSP population that are delisted during a year because of a merger. As a basis for calibrating the matching rate between targets and potential acquirers in the merger market, $\mu$, we use information from Boone and Mulherin (2007), who find that for each takeover target there are on average 3.75 interested potential acquirers 8 Therefore, we set $\mu=0.34$, which reflects the average number of firms involved in a successful takeover and the number of potential acquirers.

The three remaining parameters that govern M\&A activity in the model are the cost of merger implementation, $c_{M}$, the synergy weight of the most productive firm between the target and the acquirer, $\lambda$, and the curvature of the synergy function, $\theta$. Because our model is highly non-linear, it is not possible to associate each one of these parameters to a specific moment. However, the model provides guidance on which moments are most sensitive to a change in these parameters, and can thus be used for identification.

As discussed in section 2.5, the parameter $\lambda$ governs "who buys whom": the higher the value of $\lambda$, the higher on average will be the difference in productivity between the merged firms. To illustrate this point, we solve numerically the model for the two extreme cases of $\lambda=1$ and $\lambda=0$, and plot in Figure 4 the resulting merger synergies (Equation 5) as a input.

${ }^{8}$ More precisely, this quantity is measured as the number of potential acquirers that sign confidentiality agreements with the target company. 
function of the idiosyncratic productivity of the two merging firms, $z_{1}$ and $z_{2} 9^{9}$ The white plane in the graph represents a level of merger synergies equal to zero. For the region of $z_{1}$ and $z_{2}$ points where synergies are positive (the plotted function is above the white plane), the two matching firms decide to merge. When $\lambda=1$ (Figure $4 \mathrm{~b})$, a positive merger surplus is generated for pairs of firms with larger gaps in productivities compared to the case of $\lambda=0$, when merger activity concentrates between firms with similar productivities. To account for this effect of $\lambda$, we match the absolute difference between targets' and bidders' $\log$ Tobin's Q, scaled by the acquirer sector's yearly standard deviation of $\log (\mathrm{Q})$.

As a third calibration moment, we choose the average combined merger gains for targets and acquirers, which are set to $1 \%$, a consensus estimate of the combined cumulative abnormal returns (CAR) around the announcement of a takeover bid (see Betton, Eckbo, and Thorburn, 2008) 10 The cost of merger implementation, $c_{M}$, as well as the curvature of the synergies function, $\theta$, directly affect the merger gains. To account for variability in takeover activity over time, we match the standard deviation of the yearly fraction of CRSP firms that are taken over.

To calibrate the fixed cost of production, $c_{f}$, we compute the average annual percentage of firms in CRSP that are delisted because of liquidation, bankruptcy or other reasons related to poor performance. Finally, the cost of entry $c_{E}$ is set to match an average entry rate that yields a stationary number of firms, which corresponds to the sum of the merger and exit rates 11

To match the empirical moments in the data, we define their theoretical counterparts obtained from the numerical solution of the model in Table 3. In addition, the rates of entry and exit, and merger activity are computed in the simulation step of the solution algorithm described in Appendix B.

\footnotetext{
${ }^{9}$ The remaining parameter values used to produce the plot are reported in Panel A of Table 1, and we set $\mu=0.34, \theta=0.1, c_{M}=90, c_{E}=80$, and $c_{f}=20$.

${ }^{10}$ Our measure of total synergies differs from merger premiums. These are on average about $50 \%$ for the target and close to zero for the acquirer. We do not use this measure because merger premiums are affected by the relative size of bidder and target, and our model is silent about which of the two merging firms assumes the role of bidder or target.

${ }^{11}$ In our analysis, we use firm-level data for public companies. Lee and Mukoyama (2012), instead, base their analysis on the sample of plants covered in the Annual Survey of Manufactures from the U.S. Census Bureau, and find an entry rate of $6.2 \%$ and an exit rate of $5.5 \%$.
} 


\section{Merger Activity and Industry Dynamics}

In this section, we present the numerical results of the calibration and discuss the implications of merger activity on industry dynamics. Table 2 reports the simulated moments generated according to the calibrated parameters in Table 1. The model is able to replicate reasonably well the moments in the data, with the largest discrepancy being the overestimation of the average fraction of firms taken over in a year by $0.8 \%$. The analysis presented in this section is based on simulating the cross-sectional distribution of firms at the calibrated parameters in Table 1 for 1,000 periods, discarding the initial 200 periods to ensure convergence to the steady state. Given the simulated distributions, we use numerical integration to obtain the probabilities and moments of interest in each of the remaining periods, as described in Appendix B.

\subsection{Mergers, Entry and Exit in Industry Equilibrium}

To characterize the equilibrium industry dynamics over the business cycle, we start by describing the firms' policy functions, which determine their entry, exit and merger decisions. First, the idiosyncratic productivity thresholds for entry and exit, $\zeta_{E}(x)$ and $\zeta_{\epsilon}(x)$ respectively, are decreasing functions of the aggregate shock (Figure 5). In good times, firms with lower productivities enter the industry, whereas potential incumbents close up shop at lower levels of idiosyncratic productivity. Thus, entry is procyclical and

exit is counter-cyclical (Table 4), which is consistent with existing empirical evidence (see Campbell, 1998, and Figure 1b).

Consider now merger activity. Depending on parameter values, the model can give rise to either procyclical or counter-cyclical mergers. The former case can arise because in our specification of period profits, aggregate productivity shocks interact with idiosyncratic ones in a multiplicative way. Counter-cyclical M\&A activity, instead, takes place if the primary motive for mergers is a reduction in the fixed costs of production. This source of synergies becomes most important during recessions as firms try to avoid hitting the exit threshold. At our calibrated parameters, as Table 4 shows, the first motive prevails and merger activity exhibits strong procyclicality, a result that is in line with the empirical 
findings (Andrade, Mitchell, and Stafford, 2001, Harford, 2005, Dittmar and Dittmar, 2008, and Figure 1a). Figure 6 shows the effect of aggregate shocks on merger synergies. For very low productivity levels, the merger gains are always negative, so that no M\&As occur (Figure 6a). For higher levels of the aggregate shock, synergies can rise above zero, thus generating scope for mutually profitable merger deals (Figure 6b).

To gain deeper intuition about firms' behavior in our calibrated model, we regress the time-series of simulated rates of entry, exit and mergers on the aggregate state variables $s$, $m$ and $v$. Table 5 shows a comparison of the values of the estimated coefficients to those obtained by ignoring merger activity and setting the matching rate to zero. This comparative statics exercise shows that merger opportunities lead to an increase in the probability of entry, which, however, is not significantly related to either the mean or the variance of incumbents' idiosyncratic productivity. In the absence of merger activity, the fraction of exiting firms is counter-cyclical, it depends negatively on average idiosyncratic productivity and positively on its variance. However, when future merger options are weighted against unfavorable present aggregate or idiosyncratic conditions, the counter-cyclicality of exit reduces, and its dependence on $m$ and $v$ is attenuated.

Merger activity is heightened in periods of low average idiosyncratic productivity. In the model, this results from the restriction $\theta<1$, which characterizes a concave relationship between the productivities of target and potential acquirer, and the resulting merged firm's productivity. Instead, a convex relationship would imply that the best performer could unboundedly increase productivity and firm size through sequential mergers. Finally, the calibrated value of the parameter $\lambda, 0.55$, splits roughly equally the productivity contribution of the worst and the best performing firm in a takeover match, which yields a flat relationship between merger rates and the mean and variance of the cross-sectional distribution of idiosyncratic productivity.

Table 6 shows how the cross section of firms is affected by entry, exit and mergers. Column (1) presents summary statistics for the case in which parameters are set to their calibrated values in Table 1, but no firm turnover is allowed in the industry $\left(c_{E} \rightarrow \infty, c_{f}=0\right.$, $\mu=0$ ); in Column (2) only the matching rate $\mu$ is set to zero; and Column (3) presents the case in which mergers are also allowed. In each period, the cross-sectional distribution 
of incumbent firms' productivity reflects the history of past entry and exit decisions. A natural consequence of these decisions is that the incumbent firms' average idiosyncratic productivity in Column (2) exceeds the respective ergodic mean of the $z$ process (Column 1). The survivorship effect on the part of incumbents and the selection of potential entrants lead to an increase in firm size. Since returns to scale are decreasing, this size effect results in a drop in the operating-income-to-assets ratio and in the investment-to-assets ratio.

Merger activity produces a subsample of firms that are on average more productive (see Figure 7). The mixture of the distributions of merged and non-merged firms, which have different means, results in a cross section of incumbents with higher average but also more dispersed productivity, as can be seen by comparing Column (3) to Column (2). The operating income ratio and the average firm size measured by sales increase, while the investment ratio decreases.

With the calibrated parameters in hand, we can examine how economic behavior and the cross section of firms varies with the value of merger synergies. Columns (4) and (5) of Table 6 demonstrate the effects of reallocating the weight in the merged firm's productivity from the most efficient firm $(\lambda=1)$ to the worst $(\lambda=0)$. In the former case, the productivity gains that result from the merger are maximized and the new formed entity has a larger size and a lower investment ratio. Since the value of synergies increases, mergers take place more often, and future merger options are more valuable, which reduces exit frequency. As merger gains increase in the difference between the merging firms' productivity, the difference in Tobin's $\mathrm{Q}$ between the respective firms is highest when $\lambda=1$. Finally, when the curvature parameter $\theta$ decreases (Column 6), mergers become more frequent, and yield relatively higher synergies and merger gains.

\subsection{Impulse Responses}

In this section, we examine the effects of merger activity on industry dynamics by means of an impulse response analysis. To do so, we simulate a continuum of firms using the parameter values given in Table 1 for 1,000 periods. We then set the aggregate productivity shock $s$, the cross-sectional mean $m$ and variance $v$ of the idiosyncratic productivity shocks 
at their average steady-state levels. Figure 8 shows the impulse responses to a one standarddeviation innovation in aggregate productivity (about 3\%) when future innovations are set to zero. Two cases of particular importance are illustrated, one in which mergers among firms in the industry are possible (solid line in the graphs), and one in which merger activity is absent, but entry and exit is allowed ( $\mu=0$, dotted lines in the graphs).

Consider first the case in which the matching rate is set to zero and mergers do not occur. In this scenario, a positive aggregate shock results in a $2.9 \%$ decline of the idiosyncratic productivity threshold for entry. The exit threshold for incumbent firms also declines by a comparable amount. These changes imply a sequence of effects in the dynamics of the industry. The probability of entry rises by $63 \%$ from its steady state level, while the fraction of firm exiting declines by $38 \%$. Overall, the number of incumbent firms increases roughly by $11 \%$ following a positive aggregate shock. The favorable aggregate conditions encourage incumbents and potential entrants with relatively low idiosyncratic productivity to stay or enter the industry, respectively. As a result, mean productivity declines by $1.7 \%$ for new entrants, by $2.4 \%$ for exiting firms, and by $0.4 \%$ for incumbents. This counter-cyclical effect of entry and exit on the average idiosyncratic productivity aligns with the work of Clementi and Palazzo (2010).

When mergers are possible, synergies respond procyclically, and lead to increases in idiosyncratic productivity with a one-period lag. The fraction of firms exiting due to mergers increases by $13 \%$, and remains above its steady state rate for roughly 6 years, thus giving rise to a merger wave. The growth rate of the number of incumbent firms remains roughly similar to the case of no mergers, but this masks the effect of merger activity on entry and exit. Indeed, due to a rise in the value of future merger options, the rate of entry accelerates and the rate of exit decelerates even more strongly than in the case of no mergers. Procyclical productivity gains for merging firms more than compensate the counter-cyclical effect of entry and exit on the cross-sectional average idiosyncratic productivity, which increases by $0.35 \%$ following the aggregate shock. 


\subsection{The Evolution of the Cross-Section of Firms}

The estimates of the VAR coefficients that govern firms' expectations over future states can be used to analyze the effect of M\&As on the dynamics of the cross-sectional distribution of firm productivity (Table 7). As before, we compare two scenarios: one in which mergers are possible, and one in which they are ruled out $(\mu=0)$. Whereas in the former case higher aggregate productivity $(s)$ results in lower average idiosyncratic productivity in the future $\left(m^{\prime}\right)$, the opposite holds when firms can merge. In addition, a comparison of the expectation coefficients reveals a rich set of interactions concerning industry dynamics and M\&A activity. Both with and without mergers, persistence in productivity at the firm level translates into positive autocorrelation in average productivity at the industry level. However, when mergers are accounted for, the autocorrelation coefficient of $m$ declines, because periods with high average idiosyncratic productivity are associated with below average merger activity.

Keeping $m$ constant, higher cross-sectional dispersion in idiosyncratic productivity $(v)$ translates into a higher fraction of firms below the exit threshold. Thus, a larger proportion of low performers exit, leading to a positive association of dispersion with future mean idiosyncratic productivity. When mergers are incorporated, however, this relation-

ship weakens. The reason is that the presence of future merger options gives an incentive to poorly performing firms, which would otherwise exit, to remain in the industry.

Considering now the dynamics of the dispersion of idiosyncratic productivities, recall that a rise in aggregate productivity increases the entry rate and reduces the exit rate. Both effects lead to higher cross-sectional dispersion of productivity in the subsequent period. The presence of merger options attenuates the response of the exit rate to aggregate shocks, which in turn weakens the relationship between aggregate productivity and future dispersion in idiosyncratic productivity. In the absence of merger activity, periods with high average idiosyncratic productivity are associated with lower exit rates, and therefore higher future dispersion. Merger activity reverses this relationship, as M\&As peak in periods of low average idiosyncratic productivity, and lead in the future to a higher variance of productivity in the industry. 


\section{Conclusion}

What are the effects of merger activity on industry dynamics over the business cycle? This paper addresses this question by developing an infinite-horizon model of a competitive industry populated by firms with heterogeneous productivities. Our framework features capital accumulation, mean-reverting aggregate and idiosyncratic productivity shocks, entry, exit, and matching of firms in a merger market. Consistent with the empirical evidence, the model generates procyclical entry and merger activity, and counter-cyclical exit. This result stems from a selection effect: in good times, the threshold productivity levels for entry and exit decrease, while merger synergies, which result from productivity improvements, rise. Compared to the case in which mergers are not possible, merger opportunities induce higher entry rates and lower exit rates, and the cross-sectional distribution of firm-level productivities is characterized by higher mean and variance. Moreover, while entry and exit induce the mean of the distribution of idiosyncratic productivities to be counter-cyclical, mergers generate procyclicality.

Our paper indicates a number of potential avenues for future research. Particularly promising would be the investigation of optimal financing policies when firms can be bidders or targets in a market for corporate control. While prior work on the topic employs realoptions models that consider acquisitions as one-time irreversible investments (e.g., Morellec and Zhdanov, 2008), our model allows for repeated mergers over time. Therefore, our framework is a natural starting point to study of how firms can finance strategic growth through mergers and acquisitions, and how capital structure decisions affect their future opportunities in the merger market. 


\section{References}

Ahern, Kenneth R., 2012, Bargaining power and industry dependence in mergers, Journal of Financial Economics 103, 530 - 550.

Alimov, Azizjon, and Wayne Mikkelson, 2012, Does favorable investor sentiment lead to costly decisions to go public?, Journal of Corporate Finance 18, 519 - 540.

Andrade, Gregor, Mark Mitchell, and Erik Stafford, 2001, New evidence and perspectives on mergers., Journal of Economic Perspectives 15, 103 - 120.

Betton, Sandra, B. Espen Eckbo, and Karin S. Thorburn, 2008, Corporate takeovers, Handbook of Corporate Finance: Empirical Corporate Finance Vol. 2, edited by B. E. Eckbo, Elsevier, Oxford, UK, 291-416.

Boone, Audra L., and Harold J. Mulherin, 2007, How are firms sold?, Journal of Finance $62,847-875$.

Campbell, Jeffrey, 1998, Entry, exit, embodied technology, and business cycles, Review of Economic Dynamics 1, 371 - 408.

Clementi, Gian Luca, and Dino Palazzo, 2010, Entry, exit, firm dynamics, and aggregate fluctuations, Working Paper.

David, Joel M., 2011, The aggregate implications of mergers and acquisitions, Working Paper.

Dittmar, Amy K., and Robert F. Dittmar, 2008, The timing of financing decisions: An examination of the correlation in financing waves, Journal of Financial Economics 90, $59-83$.

Eisfeldt, Andrea L., and Tyler Muir, 2012, The joint dynamics of internal and external finance, Working Paper.

Eisfeldt, Andrea L., and Adriano A. Rampini, 2006, Capital reallocation and liquidity, Journal of Monetary Economics 53, 369-399. 
Gaughan, Patrick A., 2011, Mergers, acquisitions, and corporate restructurings, Wiley, NJ.

Gomes, João F., and Dmitry Livdan, 2004, Optimal diversification: Reconciling theory and evidence., Journal of Finance 59, 507 - 535.

Gomes, João F., and Lukas Schmid, 2010, Equilibrium credit spreads and the macroeconomy, Working Paper.

Gowrisankaran, Gautam, 1999, A dynamic model of endogenous horizontal mergers, RAND Journal of Economics 30, 56 - 83.

Harford, Jarrad, 2005, What drives merger waves?, Journal of Financial Economics 77, 529 $-560$.

Hennessy, Christopher A., and Toni M. Whited, 2007, How costly is external financing? Evidence from a structural estimation., Journal of Finance 62, 1705 - 1745.

Hopenhayn, Hugo A., 1992, Entry, exit, and firm dynamics in long run equilibrium, Econometrica $60,1127-1150$.

Jovanovic, Boyan, and Peter L. Rousseau, 2002, The Q-theory of mergers, American Economic Review 92, 198 - 204.

— , 2008, Mergers as reallocation, The Review of Economics and Statistics 90, $765-$ 776 .

Judd, Kenneth L., 1998, Numerical methods in economics, MIT Press, Cambridge, Massachusetts.

— L Lilia Maliar, and Serguei Maliar, 2011, Numerically stable and accurate stochastic simulation approaches for solving dynamic economic models, Quantitative Economics 2, $173-210$.

Khan, Aubhik, and Julia K. Thomas, 2008, Idiosyncratic shocks and the role of nonconvexities in plant and aggregate investment dynamics, Econometrica 76, 395-436.

Krusell, Per, and Anthony A. Smith, 1998, Income and wealth heterogeneity in the macroeconomy, Journal of Political Economy 106, 867. 
Lee, Yoonsoo, and Toshihiko Mukoyama, 2012, Entry, exit, and plant-level dynamics over the business cycle, Working Paper.

Levine, Oliver, 2011, Acquiring growth, Working Paper.

Morellec, Erwan, and Alexei Zhdanov, 2008, Financing and takeovers, Journal of Financial Economics 87, 556-581.

Rhodes-Kropf, Matthew, and David T. Robinson, 2008, The market for mergers and the boundaries of the firm, Journal of Finance 63, 1169-1211.

- and S. Viswanathan, 2005, Valuation waves and merger activity: The empirical evidence, Journal of Financial Economics 77, 561 - 603.

Riddick, Leigh A., and Toni M. Whited, 2009, The corporate propensity to save, Journal of Finance 64, 1729 - 1766.

Tafti, Ali, 2011, Integration and information technology effects on merger value in the U.S. commercial banking industry, Working Paper.

Tauchen, George, 1986, Finite state Markov-chain approximations to univariate and vector autoregressions, Economics Letters 20, 177 - 181.

Whinston, Michael D., 2007, Antitrust policy toward horizontal mergers, Handbook of Industrial Organization Vol. 3, edited by Mark Armstrong and Robert H. Porter, Elsevier, Oxford, UK. 


\section{Appendix}

\section{A. Data}

This appendix describes the sources of data and the construction of the empirical variables used in the paper.

To compute merger and exit activity, we use monthly data from CRSP. Our sample consists of all observations between 1926 and 2010 for listed companies (share codes of 10 or 11). For each year in the sample, we compute the number of firms active in January, the fraction of these firms that are delisted during the year because of a merger (delisting codes 200 to 299), and the fraction of firms that are delisted because of liquidation (codes 400 to 490), bankruptcy (code 574), or other reasons likely to be related to poor performance (codes 500 and 535 to 590, excluding code 573, which denotes firms that go private). These measures of merger and exit activity are similar to those in private studies (see, for example, Andrade, Mitchell, and Stafford, 2001, and Alimov and Mikkelson, 2012). The values of average merger activity and exit rate reported in Table 2 refer to the 1981-2010 period, in order to be consistent with the moments computed with other data sources. Business cycle dates in Figure 1 are from the National Bureau of Economic Research (www.nber.org).

Our second source of data is Thomson Reuters' SDC Platinum, from which we collect financial information on takeover targets and bidders, and details of M\&A deals. We start by downloading all completed transactions involving US companies between 1981 and 2010 that are categorized as mergers (deal form M) or acquisitions of majority interest (AM). We exclude deals for which: the bidder holds more than $50 \%$ of the target's shares at the announcement date of the bid; the bidder is seeking to acquire less than $50 \%$ of the target shares; there is no information on the percentage of shares involved in the transaction; either the target or the acquirer is a regulated utility (SIC codes 4900 to 4949), a financial institution (SIC codes 6000 to 6799), or a quasi-public firm (SIC codes greater than 9000); the acquirer is a foreign company; or the identity of the acquirer is not disclosed or attributable to a specific entity (e.g. "investor group").

We match the observations in SDC Platinum with the CRSP/Compustat merged (CMM) 
database. To do this, we collect the list of CUSIP codes for targets and acquirers in SDC and find the corresponding list of PERMCO codes using the CRSP translate tool. From CCM, we collect information on the following variables: Tobin's $Q$, defined as the sum of market value of equity (stock price at fiscal-year end (prccf) multiplied by number of common shares outstanding (cshpri), debt in current liabilities $(d l c)$, long-term debt $(d l t t)$ and preferred stock ( pstkl) minus deferred taxes (txditc), divided by total assets (at); net sales (sale); and profitability (operating income before depreciation ( oibp) divided by total assets). Variables are deflated to constant 2005 dollars using the GDP deflator provided by the Bureau of Economic Analysis (www.bea.gov, NIPA Table 1.1.9.).

Following Rhodes-Kropf and Robinson (2008), our measure of the difference (in absolute value) between target and acquirer $\log ($ Tobin's Q) is scaled by the standard deviation of $\log$ (Tobin's Q) in the acquirer's industry in the year of the merger transaction. To reduce the effect of outliers, we winsorize the top and bottom $1 \%$ of observations. Our final sample of merged SDC/CCM observations with non-missing values for target and acquirer Tobin's Q consists of 2,751 completed merger deals. Table 8 displays the number of observations in the sample and summary statistics, disaggregated per year.

Finally, to compute the correlation between growth in merger activity and log GDP growth we use, respectively: the log-difference in total dollar value of merger transactions in SDC Platinum per year (following Harford (2005), we drop transactions below $\$ 50$ million), and the GDP series from the Federal Reserve Economic Data (FRED) system of the Federal Reserve Bank of St.Louis (http://research.stlouisfed.org). The time period is 1981-2010.

\section{B. Details of the Computation Procedure}

This section describes the numerical strategy for non-stochastic simulation. Our model incorporates three discrete decisions that a firm may undertake: enter an industry, exit, or merge with another firm. A simple Monte Carlo simulation would involve tracking a population of firms, endogenously evolving over time given these decisions. For a simulated sample of firms, one could compute a time series of period-specific aggregate states, and use the VAR in Equation 11 to update the expectation parameters. Such an approach, however, 
encounters problems of convergence. Firms' decisions change discretely as a function of the expectation parameters, thus rendering convergence difficult. Even if this convergence issue were resolved, however, the optimization function would still be a non-smooth function of the parameters to be calibrated. This would invalidate the use of standard numerical optimization techniques.

To overcome these difficulties, we develop a non-stochastic simulation method. This approach does not rest on simulating individual firms. Instead, it tracks the cross-sectional distributions of firm's relevant variables over time. The statistics necessary to update the expectations parameters are computed by numerical integration. This approach enjoys the additional benefit of reducing the computational burden and the number of iterations required for convergence.

To illustrate this method, assume that the firm's value function $V($.$) , is computed to-$ gether with the expected continuation value $V C($.$) and policy function \kappa($.$) , for given ex-$ pectation parameters $A_{0}, A_{1}, A_{2}$. Let $\psi\left(\mu, \sigma^{2}\right)$ and $\Psi\left(\mu, \sigma^{2}\right)$ be the log-normal pdf and cdf respectively, with mean parameter $\mu$ and variance parameter $\sigma^{2}$. We generate a sequence of random aggregate shocks such that $\log \left(s_{1}\right) \sim N\left(0, \frac{\sigma_{s}^{2}}{1-\rho_{s}^{2}}\right)$ and $\log \left(s_{t+1}\right)=\rho_{s} \log \left(s_{t}\right)+\epsilon_{s t}$, where $\epsilon_{s t} \sim N\left(0, \sigma_{s}^{2}\right)$. We initiate the cross-sectional law of idiosyncratic productivity in period $1, f_{1}$, to be the ergodic distribution of an $\mathrm{AR}(1)$ in logarithm. This means that $f_{1}$ is a log-normal density with parameters $m_{1}=0$ and $v_{1}=\frac{\sigma_{\epsilon}^{2}}{1-\rho_{\epsilon}^{2}}$. Finally, we construct a grid of $z$ points, $\widehat{Z}$, according to Tauchen (1986), such that $\log (z)$ spans 5 standard deviations.

The non-stochastic simulation is based on the following iterative procedure. For every $t=1, \ldots, T:$

1. Compute the integrals $m_{t}=\int_{\mathcal{Z}} \log (z) f_{t}(z) d z$ and $v_{t}=\int_{\mathcal{Z}}\left(\log (z)-m_{t}\right)^{2} f_{t}(z) d z$;

2. Collect the vector of aggregate moments $x_{t}=\left(s_{t}, m_{t}, v_{t}\right)$;

3. Interpolate the synergies function $W($.$) in Equation 5$ at the current aggregate states $x_{t}$ to obtain the synergies as function of idiosyncratic productivity shocks only: $W_{t}\left(z_{1}, z_{2}\right)=$ $W\left(x_{t}, z_{1}, z_{2}\right)$

4. Using the bi-section method, solve $U\left(x_{t}, y\right)=c_{E}$ with respect to $y$ to find the entry threshold $\zeta_{E}\left(x_{t}\right)$ and the probability of entry $P_{E}\left(x_{t}\right)=1-\Psi\left(\zeta_{E}\left(x_{t}\right), 0, \frac{\sigma_{\epsilon}^{2}}{1-\rho_{\epsilon}^{2}}\right)$; 
5. In the same way, find the exit threshold $\zeta_{\epsilon}\left(x_{t}\right)=\operatorname{argsolve}_{z \geq 0} U\left(x_{t}, z\right)=0$ and the fraction of incumbents not exiting $P_{\epsilon}\left(x_{t}\right)=1-F_{t}\left(\zeta_{\epsilon}\left(x_{t}\right)\right)$;

6. Compute the probability that two matched firms realize positive synergies, and that a firm refuses a takeover offer and remains in the industry:

$$
\begin{aligned}
& P_{M}\left(x_{t}\right)=\int_{\mathbb{R}_{+}^{2}} 1\left(W_{t}\left(z_{1}, z_{2}\right)>0\right) f_{t}\left(z_{1}\right) f_{t}\left(z_{2}\right) d z_{1} d z_{2} \\
& P_{N}\left(x_{t}\right)=\int_{\mathbb{R}_{+}^{2}} 1\left(W_{t}\left(z_{1}, z_{2}\right)<0, z_{1}>\zeta_{e}\left(x_{t}\right)\right) f_{t}\left(z_{1}\right) f_{t}\left(z_{2}\right) d z_{1} d z_{2}
\end{aligned}
$$

7. For every gridpoint $\widehat{z} \in \widehat{Z}$, compute the integrals

$$
\begin{aligned}
& \int_{\mathbb{R}_{+}^{2}} 1\left(W_{t}\left(z_{1}, z_{2}\right)>0\right) \psi\left(\widehat{z} ; \rho_{z} \log \left(\zeta_{M}\left(z_{1}, z_{2}\right)\right), \sigma_{\epsilon}^{2}\right) \frac{f_{t}\left(z_{1}, z_{2}\right)}{P_{M}\left(x_{t}\right)} d z_{1} d z_{2} \\
& \int_{\mathbb{R}_{+}^{2}} 1\left(W_{t}\left(z_{1}, z_{2}\right)<0, z_{1}>\zeta_{e}\left(x_{t}\right)\right) \psi\left(\widehat{z} ; \rho_{z} \log \left(z_{1}\right), \sigma_{\epsilon}^{2}\right) \frac{f_{t}\left(z_{1}, z_{2}\right)}{P_{N}\left(x_{t}\right)} d z_{1} d z_{2}
\end{aligned}
$$

8. Update the distributions of the idiosyncratic productivity shocks corresponding to incumbents and to new entrants: $f_{t+1}\left(\widehat{z} \mid E_{t}=0\right)$ and $f_{t+1}\left(\widehat{z} \mid E_{t}=1\right)$, for every gridpoint $\widehat{z} \in \widehat{Z}$ using Equation 8 and Equation 9.

9. Update $N_{t+1}$ using Equation 10:

10. Collect the time series of $x_{t}=\left(s_{t}, m_{t}, v_{t}\right)$ and update firm's expectations $\left(A_{0}, A_{1}, A_{2}\right)$ by performing the VAR regression (Equation 11).

Integrations are performed by Gauss-Legendre quadrature methods, with 50 quadrature points per integration dimension. 
Table 1: Parameter values. Panel A reports the set of parameters that are chosen based on standard values in the literature (cfr. Eisfeldt and Muir (2012)). Panel B displays the values of the parameters that are calibrated to match the set of empirical moments described in the text.

\begin{tabular}{c|l|c}
\hline \hline \multicolumn{2}{l}{ Panel A: Standard parameters } & \\
\hline Symbol & Description & Value \\
\hline$\alpha$ & Curvature of the profit function & 0.75 \\
$\delta$ & Depreciation of capital & 0.15 \\
$\rho_{z}$ & Persistence of idiosyncratic productivity shock & 0.66 \\
$\sigma_{z}$ & Standard deviation of idiosyncratic productivity shock & 0.11 \\
$\rho_{s}$ & Persistence of aggregate productivity shock & 0.66 \\
$\sigma_{s}$ & Standard deviation of aggregate productivity shock & 0.03 \\
$r$ & Discount rate & 0.04 \\
\hline Panel B: Calibrated parameters & \\
\hline Symbol & Description & Value \\
\hline$\mu$ & Matching rate of targets and bidders & 0.34 \\
$c_{M}$ & Fixed cost of merger implementation & 65.57 \\
$\lambda$ & Most productive firm synergy weight & 0.55 \\
$\theta$ & Returns to scale of the synergies function & 0.34 \\
$c_{f}$ & Fixed cost of production & 18.0 \\
$c_{E}$ & Cost of entry & 56.48 \\
\hline \hline
\end{tabular}


Table 2: Calibration targets. The table contains the empirical moments targeted in the calibration. Sources of data are CRSP, Compustat and SDC Platinum. The period considered is 1981 to 2010. Entry, exit and merger rates are computed at an annual frequency. Definitions of variables and details of sample construction are provided in Appendix A. The definitions of the theoretical counterparts to the empirical moments are in Table 3.

\begin{tabular}{lcc}
\hline \hline Description of moment & Model & Data \\
\hline Average merger activity & $5.38 \%$ & $4.54 \%$ \\
Standard deviation of merger activity & 0.015 & 0.016 \\
Average absolute scaled difference in $\log (\mathrm{Q})$ of merged firms & 0.940 & 0.953 \\
Average combined merger gains & $0.088 \%$ & $1.00 \%$ \\
Average exit rate & $3.81 \%$ & $3.68 \%$ \\
Average entry rate & $8.99 \%$ & $8.22 \%$ \\
\hline \hline
\end{tabular}


Table 3: Definition of simulated moments.

\begin{tabular}{lc}
\hline \hline Tobin's Q & $\frac{V(x, z, k)}{k}$ \\
Combined merger gains for firm $i$ and $j$ & $\frac{W\left(x, z_{i}, z_{j}\right)}{V\left(x, z_{i}, k_{i}\right)+V\left(x, z_{j}, k_{j}\right)}$ \\
Sales & $s z k^{\alpha}$ \\
Operating income/Capital & $\frac{s z k^{\alpha}-c_{f}}{k}$ \\
Investment rate & $\frac{k^{\prime}-(1-\delta) k}{k}$ \\
\hline \hline
\end{tabular}


Table 4: Correlations of simulated entry, exit and merger activity with aggregate shock. The probabilities are computed in the simulation step of the solution algorithm described in Appendix B. Parameter values are shown in Table 1.

\begin{tabular}{lc}
\hline \hline Description of moment & Model \\
\hline Correlation of aggregate shock and entry & 0.8965 \\
Correlation of aggregate shock and exit & -0.9249 \\
Correlation of aggregate shock and merger activity & 0.8908 \\
\hline \hline
\end{tabular}


Table 5: Regression coefficients of simulated probabilities of entry, exit and merger on state variables. The probabilities are computed in the simulation step of the solution algorithm described in Appendix B. Parameters are set to the values shown in Table 1 for the columns denoted as "With Mergers", while $\mu$ is set to zero for the remaining two columns. $s$ denotes the aggregate productivity shock, $m$ and $v$ are, respectively, the mean and variance of the cross-sectional distribution of firms' idiosyncratic log productivity shocks, $z$. Standard errors of the OLS regression coefficients are reported in parentheses.

\begin{tabular}{l|ccc|cc}
\hline \hline & \multicolumn{3}{|c|}{ With Mergers } & \multicolumn{2}{c}{ Without Mergers } \\
\hline \multirow{4}{*}{$\log (s)$} & Prob. of Merger & Prob. of Entry & Prob. of Exit & Prob. of Entry & Prob. of Exit \\
& 0.4017 & 0.3367 & -0.5748 & 0.3076 & -1.1088 \\
$m$ & $(0.0202)$ & $(0.0185)$ & $(0.0274)$ & $(0.0176)$ & $(0.0395)$ \\
$\log (v)$ & -0.6446 & 0.0263 & -0.436 & 0.1991 & -0.8722 \\
& $(0.2000)$ & $(0.1836)$ & $(0.2716)$ & $(0.1532)$ & $(0.3449)$ \\
Constant & 0.0005 & -0.0013 & 0.0695 & 0.0614 & 0.1736 \\
& $(0.0189)$ & $(0.0173)$ & $(0.0256)$ & $(0.0398)$ & $(0.0896)$ \\
& 0.1375 & 0.0131 & 0.347 & 0.2568 & 0.8084 \\
& $(0.0915)$ & $(0.084)$ & $(0.1242)$ & $(0.1531)$ & $(0.3447)$ \\
\hline \hline
\end{tabular}


Table 6: Simulated moments for different sets of structural parameters. The starting parameter values are those in Table 1. Column (1) presents the base case of no exit, no entry and no mergers $\left(c_{E} \rightarrow \infty, c_{f}=0, \mu=0\right)$. In Column (2) there is positive entry and exit, but mergers are not possible $(\mu=0)$. Column (3) shows the simulated moments when mergers are allowed and all parameters are equal to those in Table 1 . The following four columns present comparative statics exercises: $\lambda=1$ in Column (4); $\lambda=0$ in Column (5); and $\theta=0.1$ in Column (6). The definitions of the variables are in Table 3 .

\begin{tabular}{lcccccc}
\hline \hline & $(1)$ & $(2)$ & $(3)$ & $(4)$ & $(5)$ & $(6)$ \\
\hline Sales & & & & & & \\
$\quad$ Mean & 33.518 & 39.033 & 51.826 & 55.951 & 41.738 & 65.9093 \\
$\quad$ Standard deviation & 18.358 & 19.914 & 30.785 & 34.964 & 23.297 & 46.5466 \\
\hline Operating income/Capital & & & & & & \\
$\quad$ Mean & 0.121 & 0.057 & 0.075 & 0.079 & 0.061 & 0.0848 \\
$\quad$ Standard deviation & 0.019 & 0.039 & 0.041 & 0.042 & 0.040 & 0.0476 \\
\hline Investment rate & & & & & & \\
$\quad$ Mean & 0.203 & 0.149 & 0.088 & 0.074 & 0.136 & 0.0504 \\
$\quad$ Standard deviation & 0.356 & 0.332 & 0.320 & 0.319 & 0.331 & 0.3225 \\
\hline Idiosyncratic Productivity z & & & & & & \\
$\quad$ Mean & 1.000 & 1.058 & 1.145 & 1.168 & 1.077 & 1.217 \\
$\quad$ Standard deviation & 0.146 & 0.147 & 0.179 & 0.194 & 0.154 & 0.2363 \\
\hline Calibration targets & & & & & & \\
$\quad$ Avg. Entry Rate & & 0.078 & 0.090 & 0.085 & 0.084 & 0.0831 \\
$\quad$ Avg. Exit Rate & & 0.076 & 0.038 & 0.023 & 0.068 & 0.0000 \\
$\quad$ Avg. merger activity & & & 0.054 & 0.068 & 0.010 & 0.0833 \\
$\quad$ St. Dev. merger activity & & & 0.015 & 0.008 & 0.010 & 0.0059 \\
$\quad$ Avg. merger gains & & & 0.009 & 0.016 & 0.006 & 0.0386 \\
$\quad$ Avg. log(Q) difference & & & 0.940 & 1.288 & 0.362 & 1.048 \\
\hline \hline
\end{tabular}


Table 7: VAR coefficient estimates. This table presents the coefficient estimates of the vector autoregression in Equation 11, which governs firms' expectations about the law of motion of aggregate states. The coefficients are computed using simulated data, as described in Appendix B. Parameters are set to the values shown in Table 1 for the columns denoted as "With Mergers", while the matching rate $\mu$ is set to zero for the remaining two columns. $s$ denotes the aggregate productivity shock, and $m$ and $v$ are, respectively, the mean and variance of the cross-sectional distribution of firms' idiosyncratic log productivity shocks, $z$. Standard errors are reported in parentheses.

\begin{tabular}{l|cc|cc}
\hline \hline & \multicolumn{2}{|c|}{ With Mergers } & \multicolumn{2}{c}{ Without Mergers } \\
\hline$m$ & $m^{\prime}$ & $\log \left(v^{\prime}\right)$ & $m^{\prime}$ & $\log \left(v^{\prime}\right)$ \\
\hline \multirow{4}{*}{$\log (v)$} & 0.1729 & -2.0395 & 0.6177 & 0.1409 \\
& $(0.0848)$ & $(0.8294)$ & $(0.0901)$ & $(0.3721)$ \\
$\log \left(s^{\prime}\right)$ & 0.0255 & 0.1739 & 0.0783 & -0.0202 \\
& $(0.008)$ & $(0.0784)$ & $(0.0234)$ & $(0.0967)$ \\
$\log (s)$ & -0.0176 & -0.099 & 0.0076 & -0.0125 \\
& $(0.0092)$ & $(0.0900)$ & $(0.0108)$ & $(0.0445)$ \\
Constant & 0.1099 & 1.7921 & -0.197 & 1.0246 \\
& $(0.0104)$ & $(0.1013)$ & $(0.0123)$ & $(0.051)$ \\
& 0.1971 & -2.8268 & 0.3322 & -4.0992 \\
& $(0.0388)$ & $(0.3800)$ & $(0.0900)$ & $(0.3717)$ \\
\hline \hline
\end{tabular}


Table 8: Average and median absolute value of the difference between target and acquirer $\log$ (Tobin's Q). The definition of Tobin's Q is provided in Appendix A. Values are scaled by the standard deviation of $\log$ (Tobin's Q) in the acquirer's industry in the year of the merger transaction.

\begin{tabular}{rccc}
\hline \hline Year & Observations & Mean & Median \\
\hline 1981 & 57 & 0.8495 & 0.5699 \\
1982 & 56 & 0.8976 & 0.8601 \\
1983 & 54 & 1.0193 & 0.7491 \\
1984 & 70 & 0.9601 & 0.7445 \\
1985 & 67 & 1.1777 & 0.9849 \\
1986 & 74 & 0.9970 & 0.7614 \\
1987 & 71 & 1.1361 & 0.8597 \\
1988 & 73 & 0.9715 & 0.7318 \\
1989 & 67 & 1.1177 & 0.9000 \\
1990 & 46 & 1.0737 & 0.7526 \\
1991 & 46 & 0.8740 & 0.6826 \\
1992 & 42 & 0.7762 & 0.5560 \\
1993 & 43 & 0.9953 & 0.7100 \\
1994 & 89 & 0.8486 & 0.6647 \\
1995 & 114 & 0.8438 & 0.6888 \\
1996 & 160 & 0.9134 & 0.7049 \\
1997 & 173 & 0.8378 & 0.7078 \\
1998 & 195 & 1.0109 & 0.8371 \\
1999 & 221 & 0.9525 & 0.7420 \\
2000 & 179 & 0.9576 & 0.7933 \\
2001 & 143 & 1.0571 & 0.9343 \\
2002 & 88 & 0.8844 & 0.7117 \\
2003 & 82 & 0.9231 & 0.6725 \\
2004 & 82 & 0.7956 & 0.6519 \\
2005 & 91 & 0.8963 & 0.7009 \\
2006 & 95 & 0.9499 & 0.7124 \\
2007 & 112 & 0.9743 & 0.7991 \\
2008 & 62 & 0.9741 & 0.7286 \\
2009 & 40 & 1.1125 & 1.0750 \\
2010 & 59 & 1.0204 & 0.6728 \\
\hline All & 2,751 & 0.9534 & 0.7498 \\
\hline \hline
\end{tabular}


Figure 1: Merger and exit activity in the sample of CRSP firms, 1926-2010. Shaded areas are periods of economic recession (NBER).

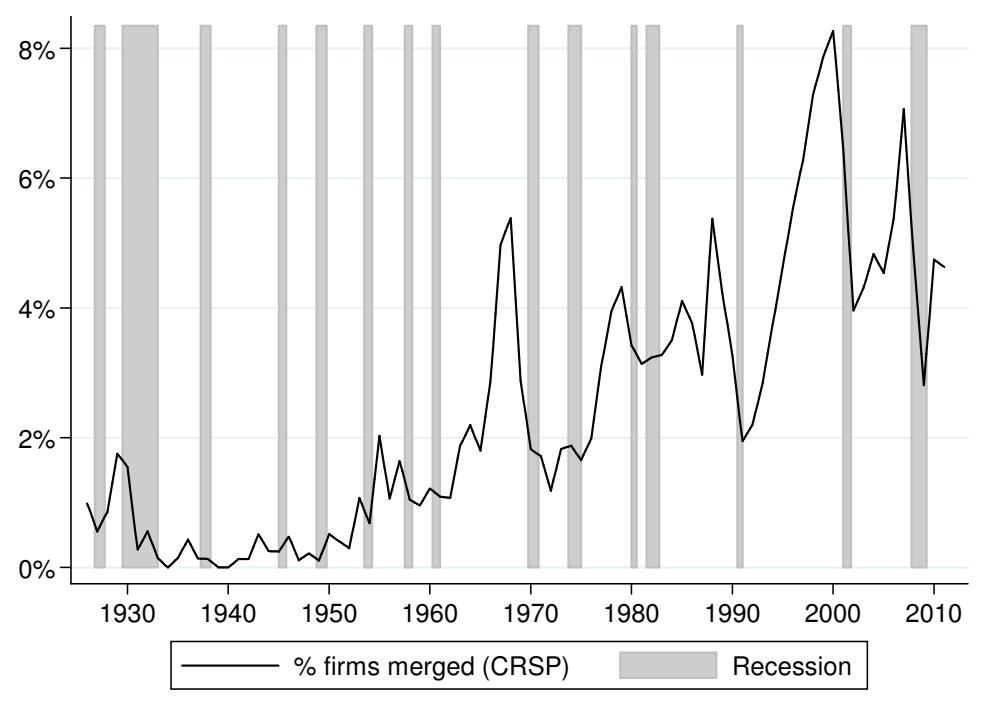

(a) Merger activity

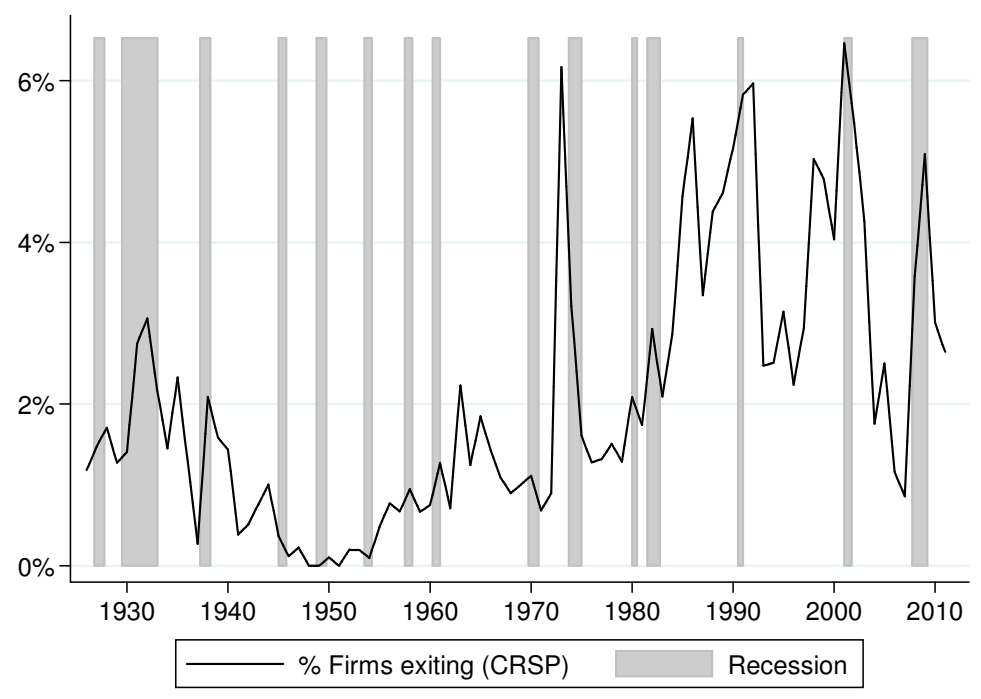

(b) Exit 
Figure 2: Timing of events within each period for incumbents and potential entrants.

\begin{tabular}{|c|c|c|c|c|c|}
\hline \multicolumn{6}{|c|}{ Incumbents } \\
\hline $\begin{array}{c}\text { Observe beginning } \\
\text { of period states } \\
(x, z, k)\end{array}$ & $\begin{array}{c}\text { Match with } \\
\text { merger partner } \\
\text { with probability } \mu\end{array}$ & $\begin{array}{l}\text { Merger } \\
\text { decision }\end{array}$ & $\begin{array}{l}\text { Investment } \\
\text { decision }\end{array}$ & $\begin{array}{l}\text { Period payoff } \\
\text { realized }\end{array}$ & $\begin{array}{c}\text { Exit } \\
\text { decision }\end{array}$ \\
\hline$t$ & & & & & \\
\hline \multicolumn{6}{|c|}{ Potential entrants } \\
\hline $\begin{array}{c}\text { Observe beginning } \\
\text { of period states } \\
(x, y)\end{array}$ & $\begin{array}{c}\text { Entry decision } \\
\text { pay cost } c_{E}\end{array}$ & & $\begin{array}{l}\text { Investment } \\
\text { decision }\end{array}$ & & \\
\hline
\end{tabular}


Figure 3: Marginal productivity of the merged firm, $z_{M}$, as a function of the productivities of the two matched firms, $z_{1}$ and $z_{2}$. In both figures, $\theta=\frac{1}{2}$.

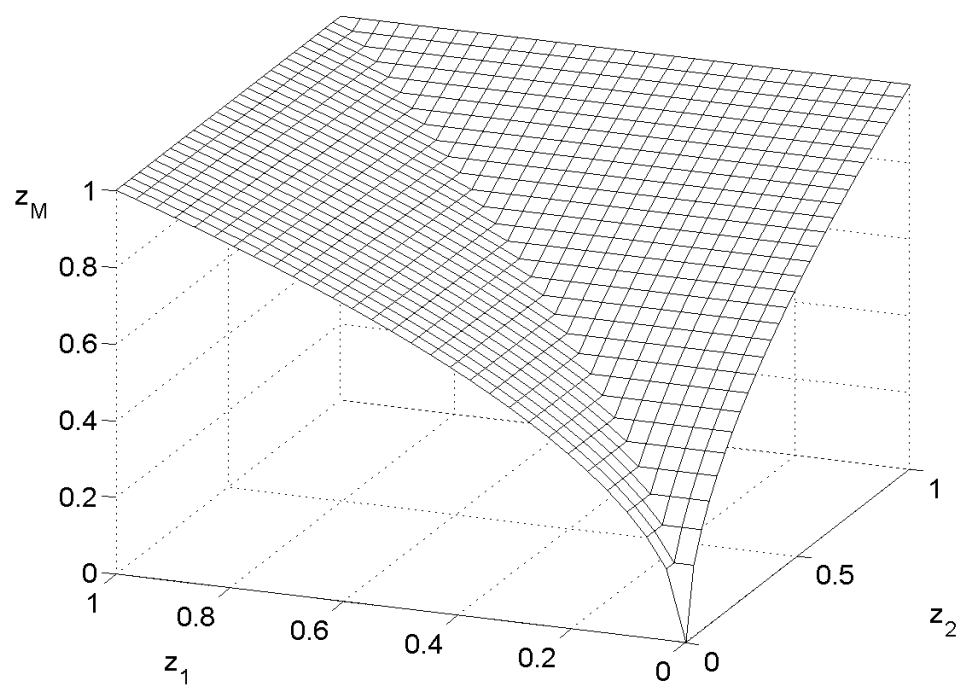

(a) $\lambda=1$

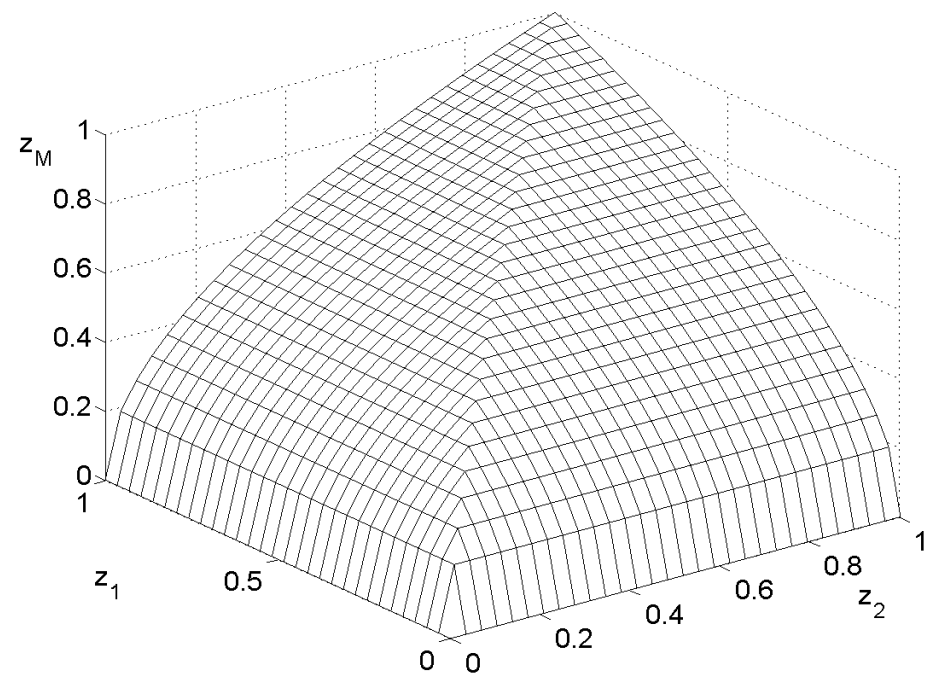

(b) $\lambda=0$ 
Figure 4: Merger synergies as a function of productivity shocks for the two matching firms, $z_{1}$ and $z_{2}$. Figure (a) shows the case for $\lambda=1$ (Q-theory), figure (b) shows the case of $\lambda=0$. The white plane is the locus of points for which merger synergies are zero. For the region of $z_{1}$ and $z_{2}$ where synergies are positive, the matched firms merge. We set $\mu=0.34, \theta=0.1, c_{M}=90, c_{E}=80$, and $c_{f}=20$. The remaining parameter values are shown in Panel A of Table 1 . States $m$ and $v$ are set at their average levels in the simulation, and $s=1$.

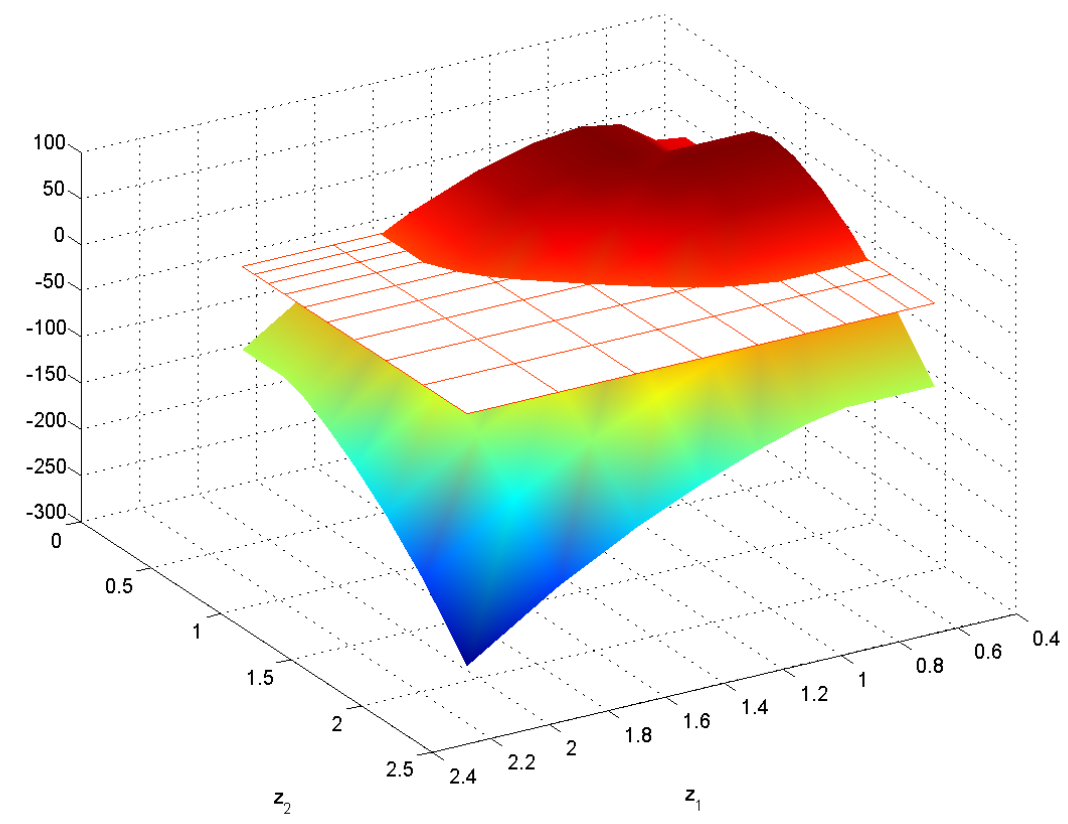

(a) $\lambda=1$

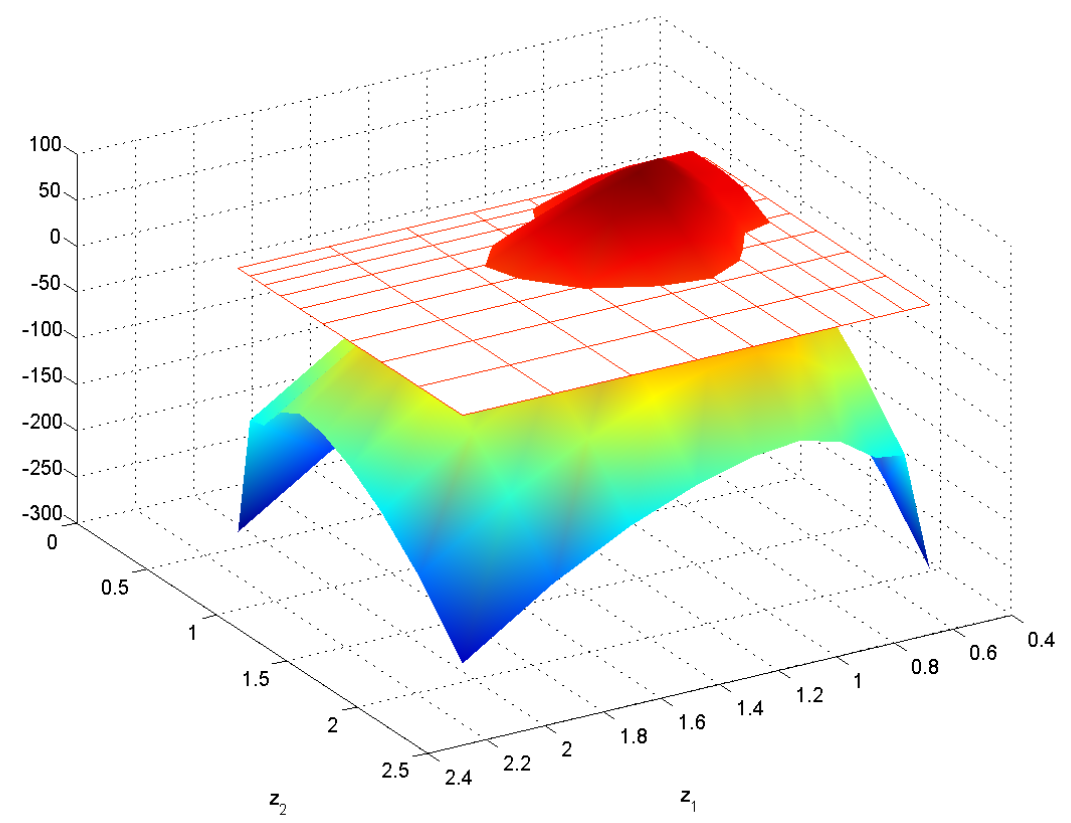

(b) $\lambda=0$ 
Figure 5: Entry and exit productivity thresholds $\left(\zeta_{E}, \zeta_{\epsilon}\right)$ as a function of the aggregate shock $(s)$. Parameter values are shown in Table 1 . States $m$ and $v$ are set at their average levels in the simulation.

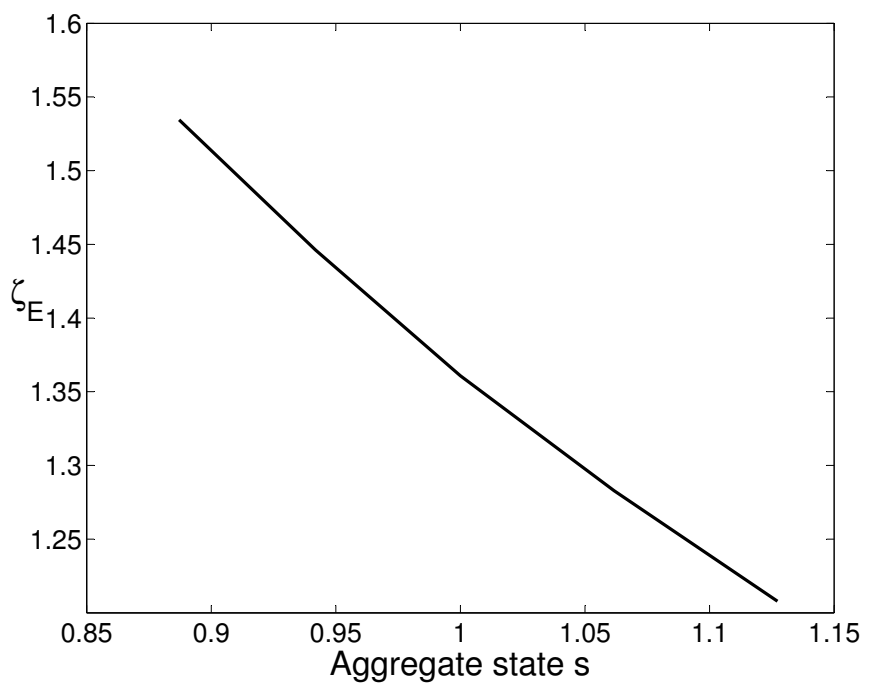

(a) Entry threshold $\left(\zeta_{E}\right)$

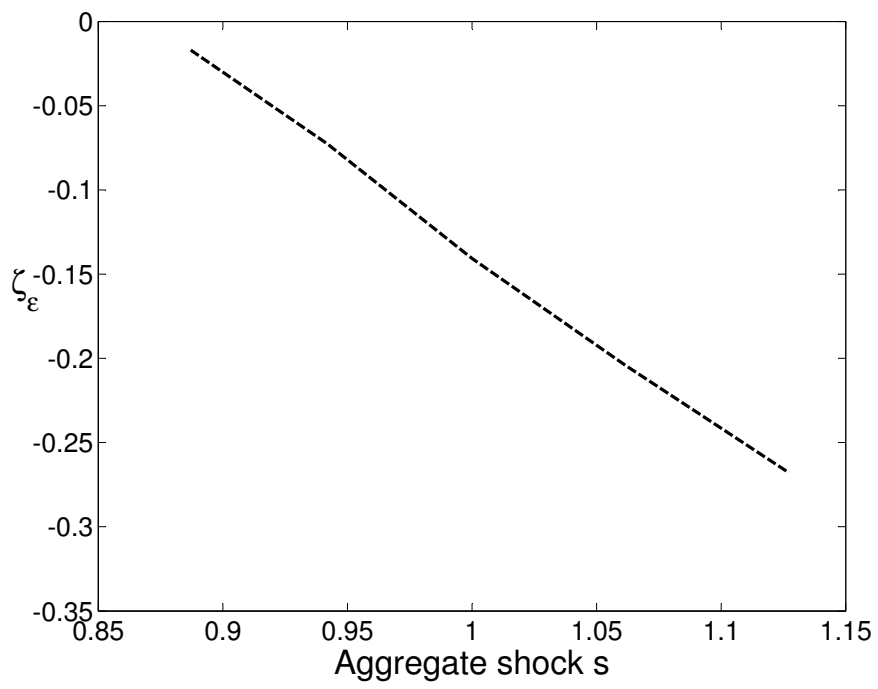

(b) Exit threshold $\left(\zeta_{\epsilon}\right)$ 
Figure 6: Merger synergies as a function of productivity shocks for the two matching firms, $z_{1}$ and $z_{2}$. Figure (a) shows the case for $s=0.8871$ (low aggregate productivity), figure (b) shows the case of $s=1.1273$ (high aggregate productivity). The white plane is the locus of points for which merger synergies are zero. For the region of $z_{1}$ and $z_{2}$ where synergies are positive, the matching firms merge. Parameter values are shown in Table 1 . States $m$ and $v$ are set at their average levels in the simulation.

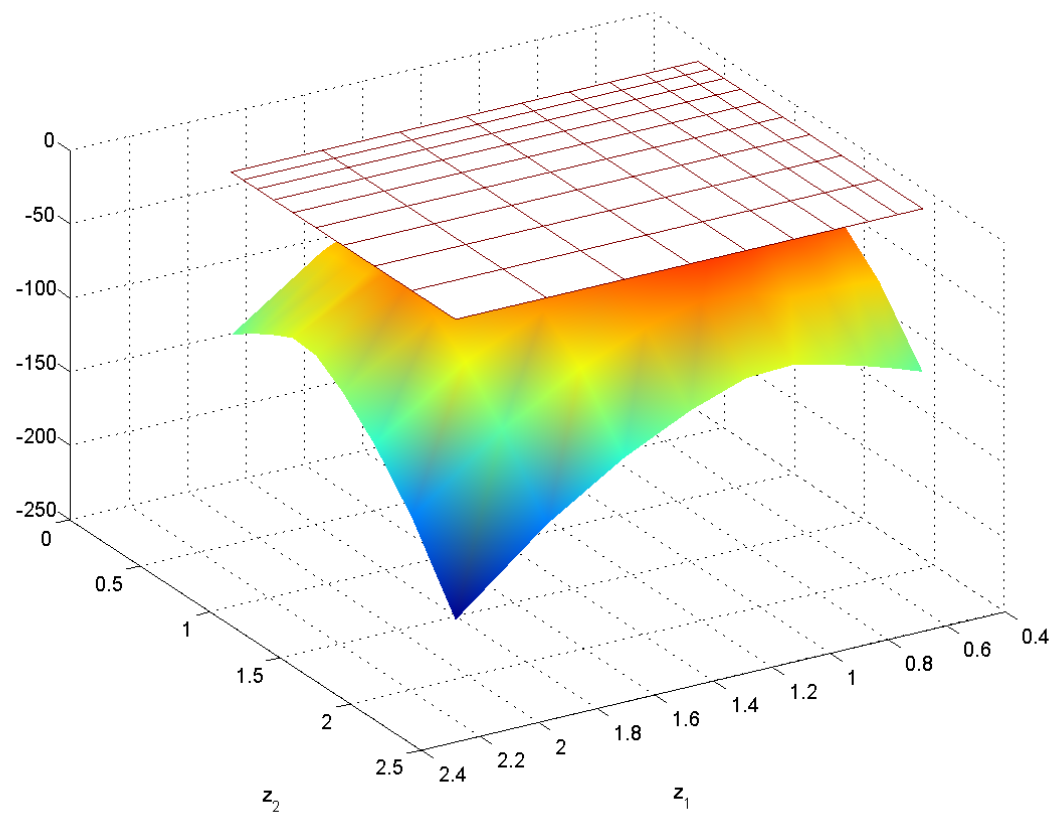

(a) Low aggregate productivity

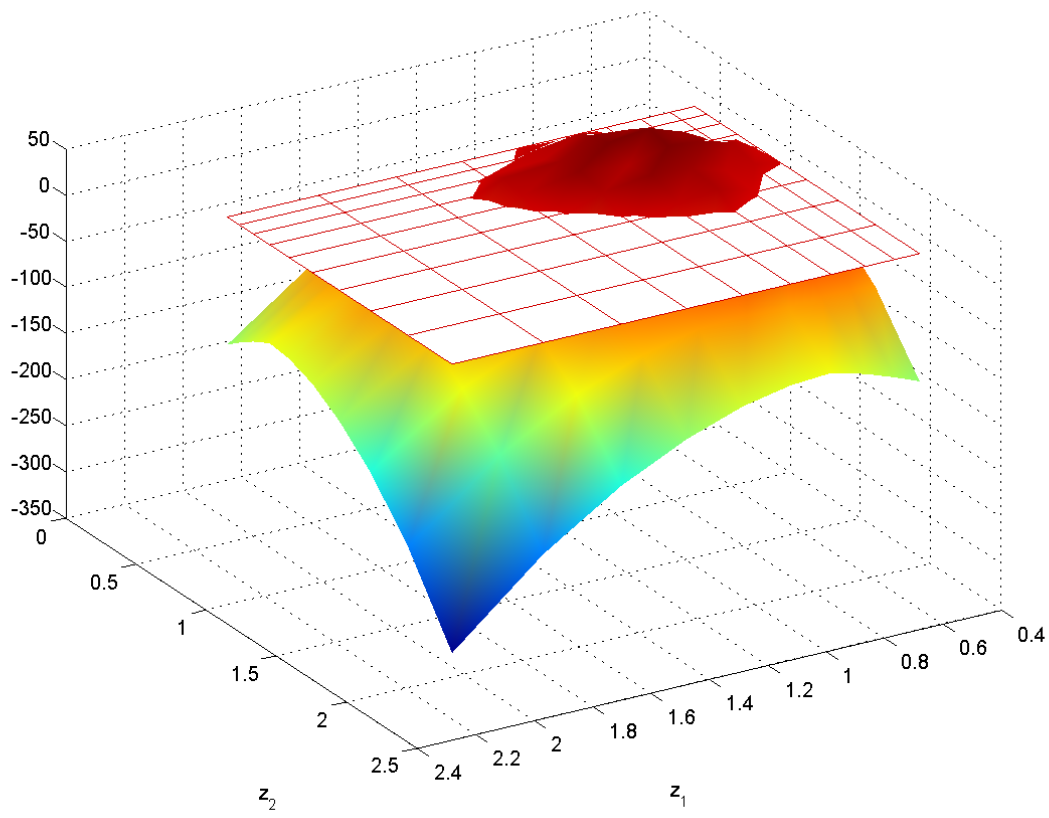

(b) High aggregate productivity 
Figure 7: Simulated cross-sectional distribution of firms' idiosyncratic productivity shocks, $z$. Figure (a) shows the distribution of $z$ for incumbent firms and for new entrants in the industry, for the case in which there are no mergers, $\mu=0$. Figure (b) shows the distribution of $z$ for incumbent firms, entrants, merging firms, and stand-alone firms - firms that were matched but decided not to merge. Parameters are set to the values presented in Table 1 . The distributions derive from pooling 800 time-specific distributions obtained by non-stochastic simulation.

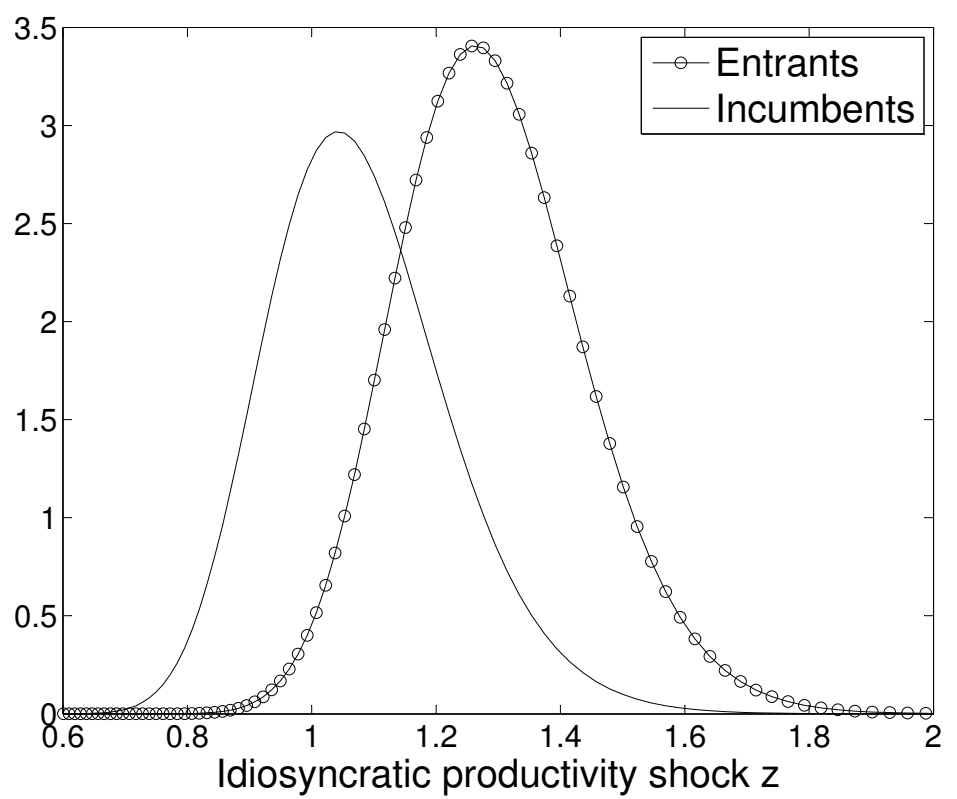

(a) Entry, exit, without mergers

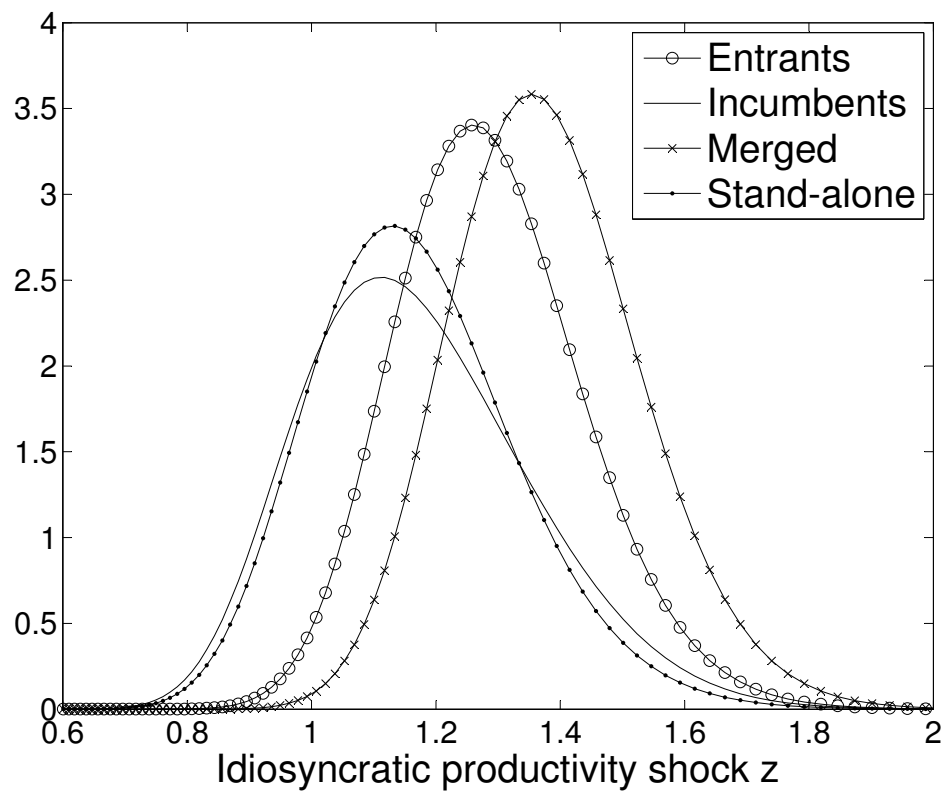

(b) Entry, exit, mergers 
Figure 8: Impulse response functions for a positive shock to aggregate productivity $(s)$. Parameters are set to the values shown in Table 1. Impulse responses are computed using the simulated data, as described in Appendix B.

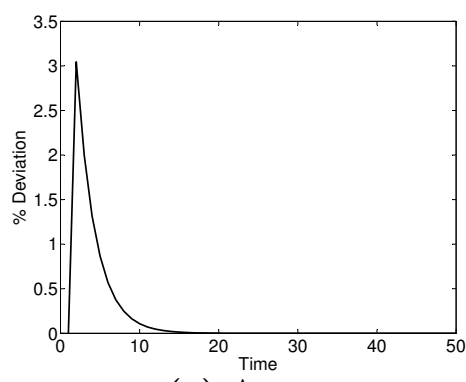

(a) Aggregate shock

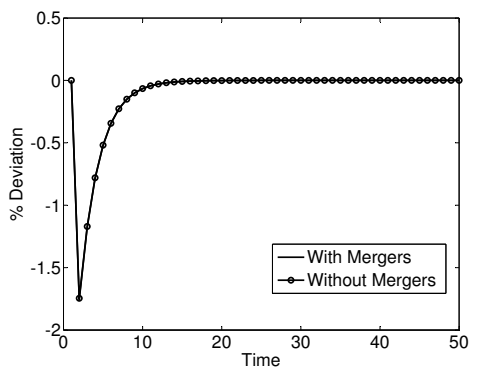

(d) Entrants' avg. id. productivity shock $z$

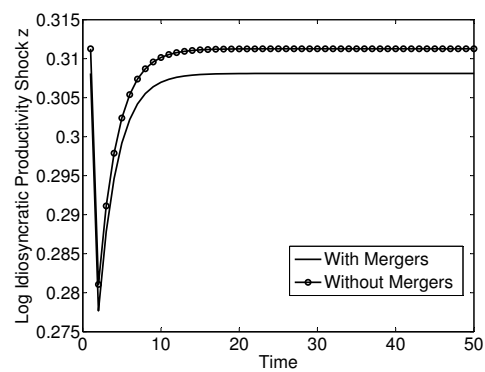

(g) Entry threshold

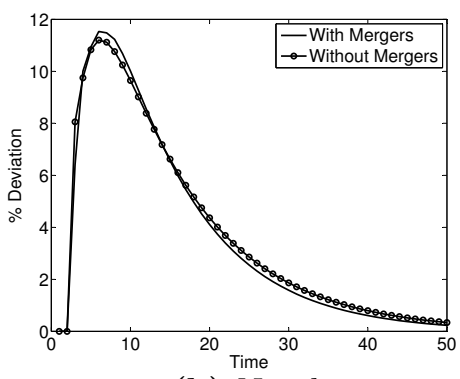

(b) Number of firms

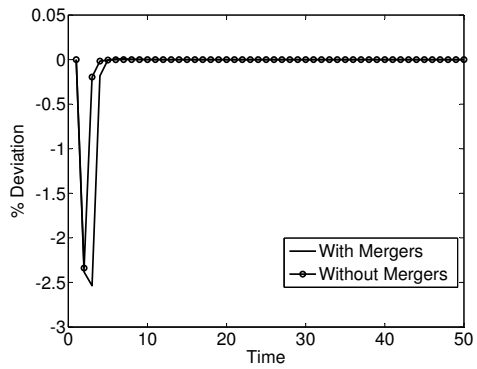

(e) Exitors' avg. id. productivity shock $z$

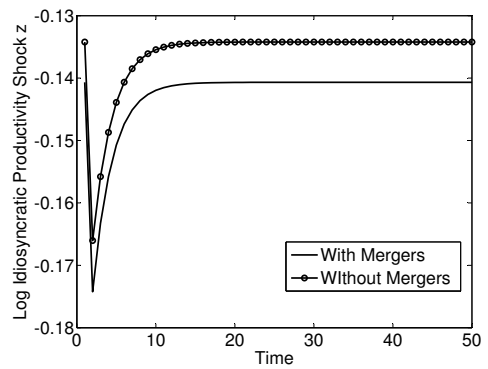

(h) Exit threshold

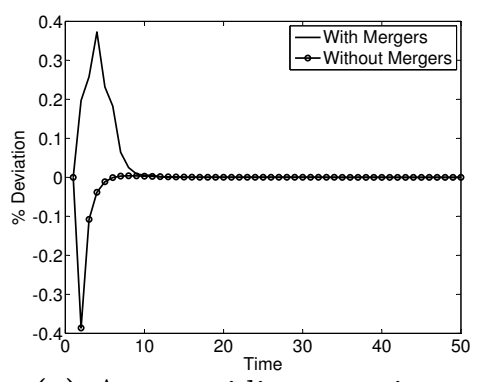

(c) Average idiosyncratic productivity shock $z$

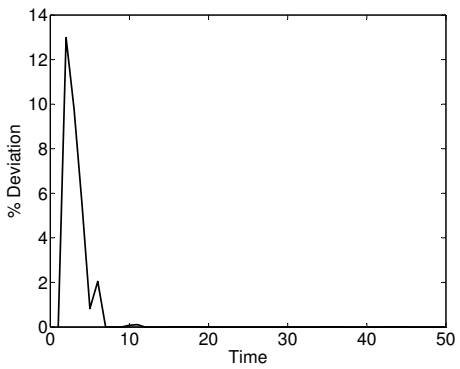

(f) Merged firms' avg. id. productivity shock $z$

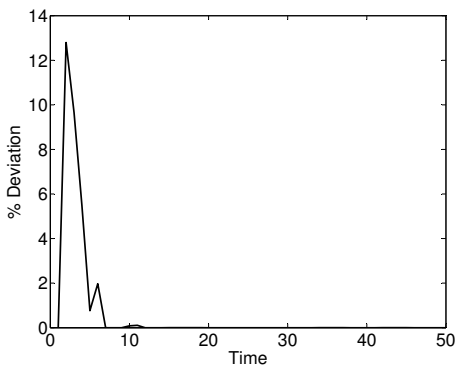

(i) Merger rate 